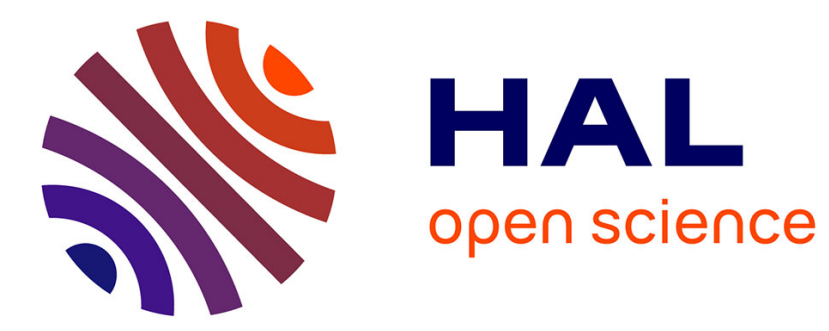

\title{
Phénomène, culture et tradition : statuts et rôles du Campaniforme au IIIe millénaire dans le Sud-Est de la France
}

Olivier Lemercier

\section{- To cite this version:}

Olivier Lemercier. Phénomène, culture et tradition : statuts et rôles du Campaniforme au IIIe millénaire dans le Sud-Est de la France. Bulletin de la Société préhistorique française, 1998, tome $95\left(n^{\circ} 3\right)$, pp.365-382. halshs-00087834

\section{HAL Id: halshs-00087834 \\ https://shs.hal.science/halshs-00087834}

Submitted on 27 Jul 2006

HAL is a multi-disciplinary open access archive for the deposit and dissemination of scientific research documents, whether they are published or not. The documents may come from teaching and research institutions in France or abroad, or from public or private research centers.
L'archive ouverte pluridisciplinaire HAL, est destinée au dépôt et à la diffusion de documents scientifiques de niveau recherche, publiés ou non, émanant des établissements d'enseignement et de recherche français ou étrangers, des laboratoires publics ou privés. 


\title{
Phénomène, culture et tradition : statuts et rôles du Campaniforme au Ille millénaire dans le Sud-Est de la France
}

\begin{abstract}
Résumé
Le " Campaniforme", par la variabilité de ses manifestations dans le temps et dans l'espace, semble recouvrir plusieurs entités différentes qui ne peuvent être appréhendées de façon globale. L'approche régionale, dans le Sud-Est de la France, permet de mettre en évidence la nature d'un premier "Phénomène Campaniforme" qui se diffuse dans les sociétés du Néolithique final. Ce phénomène, relativement marginal, produit rapidement une véritable "Culture Campaniforme", autonome et divisée en faciès géographiques dont les relations avec les cultures locales qui perdurent sont probables. Cette culture se poursuit au début de l'âge du Bronze ancien sous la forme d'une tradition qui intègre de nouveaux éléments d'origine étrangère. Le rôle de ce Phénomène Campaniforme et de la culture qui en est issue est replacé dans une perspective de l'évolution des sociétés du Ille millénaire.
\end{abstract}

\begin{abstract}
The "Bell Beaker" complex should not be globally perceived, because it seems to include several different entities, as shown by ils variations in space and time. A regional approach, in south-eastern France, outlines the existence of a first "Bell Beaker Phenomenon" and its spread in Late Neolithic societies. This relatively marginal phenomenon quickly becomes an actual independent "Bell Beaker Culture", with différent geographical facies. These may have been in contact with surviving local cultures. In the Early Bronze Age, a "Bell Beaker Tradition" integrates some new elements brought in from outside, and seems to extend the Bell Beaker culture. The role of this "Bell Beaker Phenomenon" and this induced culture is regarded here as part of the evolution of societies during the third millennium BC.
\end{abstract}

\section{INTRODUCTION}

\section{De Saint-Germain-en-Laye à Riva del Garda}

L'insertion du Campaniforme, dans son contexte chronologique et culturel du Ille millénaire dans le Sud-Est de la France, a été envisagée afin de répondre à la question de la séance thématique de la Société Préhistorique Française, de novembre 1997. Le texte présenté lors de cette réunion a fait, depuis, l'objet de nombreuses modifications afin de tenir compte des études les plus récentes et des différents points de vue échangés lors du Congrès Bell Beaker Today de Riva del Garda.

\section{Place et rôle du Campaniforme}

Comprendre le Campaniforme à l'échelle de sa diffusion en Europe semble toujours une tâche difficile. La raison de cet échec répété est probablement la variabilité de ce Campaniforme, tant dans ses manifestations que dans sa nature même, à la fois dans le temps et dans l'espace. II est nécessaire, en complément des études spécialisées qui envisagent les " universaux " du Campaniforme, de revenir à des approches régionales, permettant de préciser le contexte d'apparition et d'évolution de ce " complexe ". 
Le cadre géographique étant défini en préalable, le contexte du IIP millénaire peut être précisé. Dans ce cadre, les principales données sur le Campaniforme sont rappelées et discutées brièvement, car elles ont fait l'objet de nombreuses publications (référencées dans Lemercier 1996, 1997a et 1998) et un nouvel état des connaissances à l'échelle du Midi méditerranéen a été récemment réalisé (Guilaine, Claustre, Lemercier et Sabatier à paraître).

Une division chronologique du Campaniforme est proposée afin de comprendre l'évolution de sa place et de son statut dans son environnement culturel. Le rôle du Campaniforme, dans un cadre régional, est enfin abordé dans une perspective plus large.

\section{LE CONTEXTE ET LES DONNEES}

\section{Le cadre géographique}

\section{Une région Campaniforme}

Le Sud-Est de la France envisagé (fig. 1) correspond à l'aire principale de répartition du mobilier caractéristique du groupe Campaniforme Rhodano-Provençal reconnu et bien décrit par Jean Courtin (Courtin 1967, 1974). Cette aire a été étendue aux limites administratives des départements concernés. La présence, maintenant reconnue, de mobilier attribuable à ce groupe dans des secteurs plus septentrionaux en France et en Italie du Nord, ne correspond qu'à quelques ensembles isolés dans des contextes différents et peut, sans doute, être interprétée en terme d'échanges ou de déplacements à longue distance.

\section{Définition géographique de la région}

Cette région englobe la rive gauche du bassin inférieur du Rhône, depuis le département de I'Isère au nord jusqu'à la frontière italienne à l'est et les marges rhodaniennes du Gard et de l'Ardèche à l'ouest.

\section{Une géographie contrastée et ses conséquences}

Ce Sud-Est comprend un grand nombre d'ensembles géographiques distincts recouvrant une grande variété de milieux (côtes, plaines, vallées larges, régions vallonnées, moyennes et hautes montagnes) conditionnant les possibilités d'implantations et d'activités humaines mais aussi et surtout une recherche archéologique qui ne saurait rendre compte que très partiellement d'une géographie préhistorique. Comme dans d'autres régions, la présence d'importantes concentrations mégalithiques, dans les Alpes-Maritimes et l'est varois ainsi qu'en Ardèche, a très longtemps conditionné une archéologie funéraire et monumentale au détriment de la connaissance des sites d'habitat.

La région définie comprend actuellement près de 270 sites connus ayant livré du mobilier attribuable au Campaniforme (Lemercier 1996 et 1997a).

\section{Le contexte culturel du Ille millénaire}

Le troisième millénaire est marqué, dans le Sud-Est de la France, par de nombreuses cultures matérielles dont l'organisation géographique et chronologique demeure, malgré le nombre des travaux récents (D'Anna 1995a et b), à préciser (fig. 2).

\section{La fin de l'unité du Néolithique moyen}

Le morcellement de la grande unité supposée du Néolithique moyen Chasséen semble 
passer, dans cette région, par une phase de transition encore mal reconnue, Chasséen terminal ou Néolithique récent, dont les séries vauclusiennes de la Grotte Goulard à Ménerbes et des sites de Mondragon - Les Juilléras (Lemercier et al. à paraître), Mondragon - Le Duc et Grillon le Brave - La Blaoute pourraient témoigner et même montrer une certaine unité pouvant être rapprochée des séries languedociennes de l'Avencas et de la Mort des Anes (Gutherz 1984).

\section{Les cultures matérielles et la chronologie du Néolithique final}

Le Néolithique final ancien est marqué en Provence par le groupe de Fraischamp, lui aussi reconnu en Vaucluse, et par la phase ancienne du Couronnien. Ces deux groupes sont contemporains du groupe de Ferrières, sur la rive droite du Rhône. Le Néolithique final récent, marqué en Languedoc par les différents faciès du groupe de Fontbouisse, connaît à l'Est du Rhône une situation plus complexe où il est divisé par André D'Anna en deux phases chronologiques par l'apparition du Campaniforme autour de 4200 BP.

La première phase voit l'apparition en nombre des sépultures dolméniques, et si le groupe Couronnien semble perdurer, de nouvelles cultures matérielles font leur apparition. II s'agit du groupe Rhône-Ouvèze (Mùller et D'Anna 1986), qui est probablement un faciès extrême oriental du groupe de Fontbouisse, et du groupe du Nord-Vaucluse. L'articulation de ces trois ensembles reste à préciser.

La phase finale, marquée par l'apparition du Campaniforme, voit probablement perdurer ces trois groupes.

\section{Les changements techniques et sociaux du Néolithique final}

Les sociétés qui occupent ce troisième millénaire connaissent aussi des changements plus importants que ceux des caractéristiques techniques et stylistiques de leur culture matérielle. II s'agit, tout d'abord, d'une période d'essor démographique bien montré par le nombre de sites : environ 600 pour le Néolithique final et pour la seule région provençale. Cette période est aussi caractérisée par un morcellement du territoire en groupes culturels et faciès bien individualisés qui rivalisent d'ostentation avec l'apparition des enceintes et des sépultures mégalithiques de plus en plus nombreuses et monumentales, pouvant prendre des proportions et des aspects exceptionnels comme pour les hypogées de Fontvieille. De réels conflits, dans ce cadre, ne sont pas à exclure avec les exemples des " couches de guerre " de Roaix - Les Crottes.

Le développement rapide et la multiplication des biens à caractère non utilitaire comme l'art anthropomorphe et la première métallurgie s'inscrivent dans la même idée. C'est dans ce contexte que le Campaniforme apparaît dans le Sud-Est de la France (D'Anna 1995a et b).

\section{Le Campaniforme : données historiques}

Le Campaniforme est reconnu dans le Sud-Est de la france dès la fin du XIXe siècle, mais c'est surtout dans la deuxième moitié du XXe que de nombreux sites sont fouillés et livrent un mobilier qui en fait l'une des régions les plus riches de France (Courtin 1974, Lemercier 1998, Treinen 1970).

\section{Le mobilier Campaniforme}

Le mobilier Campaniforme comprend avant tout une céramique ornée. Le registre des formes, assez diversifié, correspond néanmoins, sur toute la région, à des normes strictes. C'est surtout le décor, très riche et très varié dans ses techniques comme dans ses motifs, qui, par une disposition assez standardisée, permet de donner une certaine unité à un mobilier abondant. D'autres types d'objets se sont ajoutés, par association préférentielle au fur et à mesure des découvertes, à la " culture matérielle Campaniforme ". Une industrie lithique peu différente de celle reconnue pour d'autres cultures comprend quelques outils 
particuliers comme les armatures de flèche à ailerons et pédoncule. Certaines parures comme les pendeloques arciformes, les boutons à perforation en $\mathrm{V}$ et certains objets très spécifiques comme les " brassards d'archer " ont rapidement été considérés comme attribuables au Campaniforme. II en va de même pour certains objets en cuivre comme les pointes de Palmela, certains petits poignards et les alênes bipointes à section carrée (Del Castillo 1928, Courtin 1974, Guilaine 1976).

Une céramique commune est, plus récemment, venue s'ajouter à ce mobilier spécifique du Campaniforme. Reconnue par Jean Courtin dès les années 1960 (Courtin 1974) dans les grottes des Gorges du Verdon, elle a été identifiée comme appartenant à un ensemble Rhodano-Rhénan (Gallay 1986) puis étudiée et classée en une nouvelle typologie (Besse 1996). Cette céramique commune Campaniforme comprend dans le Sud-Est des formes à fond plat, de petites formes de type tasse, bol, pichet, des cordons à section triangulaire en position pré-orale, simples ou doubles, des perforations traversières en ligne sous le bord. De nombreux sites ont maintenant livré ce type de céramique en association avec des vases campaniformes ornés.

\section{La place chronologique du Campaniforme}

Les datations radiocarbones de contextes campaniformes demeurent assez rares dans le Sud-Est de la France avec 18 mesures recensées par Philippe Sabatier (Guilaine, Claustre, Lemercier et Sabatier à paraître). Ces dates s'échelonnent sur la totalité du troisième millénaire et la première moitié du second pour la phase épicampaniforme. Elles montrent d'importantes plages de recouvrement avec les datations des groupes culturels du Néolithique final : le groupe de Fontbouisse pour le Languedoc et les groupes couronnien récent, Rhône-Ouvèze et Nord-Vaucluse pour la Provence. Les marges d'incertitude liées à ces dates sont importantes et ne permettent pas de conclure sur la place temporelle précise du Campaniforme ni sur son possible synchronisme avec un ou plusieurs des groupes culturels régionaux. II est toutefois important de retenir qu'en terme de datations, ces groupes et le Campaniforme ne s'excluent pas de façon stricte.

Les stratigraphies, très rares pour la période, dans cette région, ne livrent guère plus d'informations. Les objets campaniformes y sont souvent mélangés à des objets du Néolithique final dans des niveaux uniques. II existe quelques cas de successions stratigraphiques entre le Néolithique final et le Campaniforme, mais elles ne peuvent témoigner de la stricte postériorité du Campaniforme par rapport au Néolithique final, considérant la longue durée de ce dernier.

Les associations de mobiliers campaniformes et de mobiliers caractéristiques du Néolithique final sont très nombreuses à la fois dans les sites stratifiés en grottes et abris et sur les sites de plein air. Les mêmes associations sont considérées selon les différents chercheurs soit comme la preuve d'un synchronisme, soit comme le résultat évident de remaniements.

Plusieurs types d'associations sont connus:

- les sites ne livrant que du mobilier Campaniforme sont très rares. Si certains contextes homogènes sont signalés, il n'est pas rare que quelques objets différents soient présents ;

- de même, de très nombreux sites attribués aux différents groupes du Néolithique final, livrent quelques fragments de céramique ornée Campaniforme ;

- les sites qui livrent en nombre des documents attribués au Campaniforme et aux groupes locaux sont plus rares mais doivent être pris en compte avec les exemples de Avignon - La Balance, Eyguières - Les Barres et La Couronne - Collet-Redon.

\section{La chronologie interne du Campaniforme}

Comme dans d'autres régions, seule la céramique ornée permet une bonne identification du Campaniforme. C'est donc à partir de celle-ci qu'une chronologie interne du Campaniforme a pu être élaborée et proposée par Jean Guilaine (Guilaine 1976) (fig. 3) : 
Phase ancienne : les décors linéaires ou en bandes sont couvrants et réalisés à la cordelette (AOC) ou au peigne (AOO, maritimes) et existent aussi des décors mixtes associant les deux techniques. Le gobelet classique est la seule forme connue portant ce type de décor (fig. 4 et 5).

Phase moyenne ou de transition : les décors présentent un mélange du décor maritime à bandes alternes à hachures obliques avec des nouveaux thèmes (triangles, chevrons) réalisés au peigne et parfois associés à des motifs estampés. Ces décors se trouvent sur des gobelets classiques mais aussi sur de nouvelles formes comme les écuelles et les coupes tronconiques (fig. 5 et 6 ).

Phase récente : le décor au peigne est rare mais toujours présent. Les décors les plus fréquents sont incisés et estampés. La technique, les motifs et leur disposition sont très variés et constituent des groupes régionaux marqués : pour le Sud-Est, le groupe RhodanoProvençal. Les formes céramiques sont plus nombreuses et plus variées, elles aussi : gobelets, bols, jattes carénées, écuelles, bouteilles, coupes à pied... (fig. 7 et 8 )

Phase épicampaniforme : les décors sont marqués par une tradition Campaniforme avec des motifs incisés, imprimés ou barbelés et rarement réalisés au peigne. Les formes céramiques les plus courantes sont de type Bronze ancien : urnes, vases biconiques, jattes, coupes, pichets, cruches, tasses à anse... (fig. 9 et 10)

\section{Une nécessaire révision (temps et géographie)}

Depuis son élaboration, cette typo-chronologie a été reprise par de très nombreux chercheurs (Treinen-Claustre 1989, Barge-Mahieu 1992) qui l'ont considérée comme un acquis.

Certains (Salanova 1997a, 1998), en revanche et pas forcément à tord, reprochent à cet essai de ne reposer que sur la reconnaissance de trop rares ensembles homogènes, en l'absence de stratigraphie connue pour le développement interne du Campaniforme. Sans rejeter trop hâtivement cette typo-chronologie, il faut bien lui reconnaître quelques problèmes à l'usage. En réalité, Jean Guilaine a lui même, dès le début (Guilaine 1976), puis surtout dernièrement (lors du congrès de Riva), envisagé la possibilité d'un schéma moins simple et plus ouvert. En effet, de nombreuses séries, provenant parfois d'ensembles clos comme la sépulture de Soyons en Ardèche, livrent des associations d'objets correspondant à des phases typologiques différentes. Si la présence de décors au peigne dans des contextes du Campaniforme récent a été signalée dans la typologie elle même, il semble que les types de vases les plus anciens perdurent assez longtemps dans la séquence. De plus, un paramètre géographique semble intervenir et perturber sensiblement le schéma général. En effet, si le Midi de la France est marqué par des groupes évolués du Campaniforme, caractérisés par l'emploi de nouvelles techniques de décor, il n'en va pas de même pour les régions situées immédiatement au nord, dans la vallée du Rhône, ou sur le versant italien des Alpes. Ces régions présentent des séries de céramiques décorées essentiellement au peigne, avec des motifs évolués qui peuvent correspondre aux types définis dans la phase 2 de Jean Guilaine. Les associations de mobiliers observées, dans la vallée du Rhône par exemple (Lemercier 1997b), montrent clairement le synchronisme entre les vases du groupe Rhodano-Provençal de la phase récente et ces objets d'obédience plus septentrionale qui perdurent donc assez longtemps et ne se limitent pas à la tranche chronologique de la phase 2 définie.

II semble que cette typo-chronologie peut être, si on lui admet une certaine souplesse à l'usage, une image relativement fidèle de la succession générale des styles décoratifs et des formes de la céramique du Campaniforme.

\section{Temps radiocarbone et durée préhistorique}

Les problèmes de cette typo-chronologie renvoient très probablement à la fausse image du 
Campaniforme qui nous est donnée par les datations isotopiques. Le temps radiocarbone, lié aux intervalles d'incertitude des mesures, est à l'évidence un temps trop long. Certaines observations indiquent une durée relativement brève pour le groupe Rhodano-Provençal, de part le synchronisme probable entre de nombreux sites voisins comme Saint-Côme - Le Bois Sacré, Calvisson - Maupas et Caissargues - Le Moulin Villard dans le Gard (Convertini à paraître) et Simiane - Le Col Sainte-Anne, La Couronne - Collet-Redon et Martigues - Ponteau dans les Bouches-du-Rhône (Lemercier en préparation).

Il est, en fait, très probable que le Campaniforme se développe dans une durée relativement brève dans le second et le troisième quart du IIP millénaire, avec une courte perduration probable pour la phase épicampaniforme.

\section{INSERTION DU CAMPANIFORME : UNE RELECTURE DES DONNÉES}

\section{Le Campaniforme ancien : le phénomène}

\section{Un mobilier de prestige}

La céramique ornée caractéristique de la phase ancienne du Campaniforme (fig. 4), et correspondant au " standard " défini par Laure Salanova (Salanova 1997a et b, et ce volume) semble relativement rare dans le Sud-Est de la France. De nombreux fragments de céramiques portent des décors réalisés au peigne ou à la cordelette dont la disposition, linéaire ou organisée en bandes de hachures, et pourraient être attribués à ce type d'objet. Néanmoins leur extrême fragmentation et la possibilité pour les vases " plus évolués " de la phase 2 (fig. 6) de porter partiellement un décor de ce type invitent à la prudence, dans l'attente de comptages précis.

Certains vases peuvent donc, cependant, être attribués à cette première présence Campaniforme. II s'agit pour l'essentiel de vases de type maritime. Comme Jean Guilaine l'a rappelé à plusieurs reprises, aucun objet du Midi de la France n'est réellement comparable aux grands gobelets $A O C$ ou $A O O$ du nord de l'Europe. Outre sa probable rareté, la principale caractéristique de cette céramique est sa qualité et son caractère allochtone, au moins pour certains vases. Le cas du vase de la sépulture de Forcalquier - La Fare (fig. 11 et 12) (Müller et Lemercier 1994 et en préparation, Müller, Lemercier et Bouville 1997, Lemercier, Müller et Bouville 1996) est à ce titre intéressant. II s'agit d'un gobelet orné dans le style maritime mixte (peigne et cordelette). Son aspect général, la nature de son décor (étude L. Salanova) et sa technologie avec la présence de chamotte (étude F. Convertini) le distinguent nettement des productions locales, beaucoup plus frustes, qui lui sont associées. II s'agit d'un " beau " vase. La céramique lisse qui peut être associée à ces objets comprend deux catégories bien distinctes. La céramique fine peut correspondre, selon les cas, à une production locale attribuable aux groupes locaux du Néolithique final, comme c'est le cas pour la sépulture de Forcalquier - La Fare ou à des objets de typologie Campaniforme comme dans la région voisine sur le site de Trèbes - Le Mourral (Vaquer 1998) où la céramique lisse associée aux vases ornés est composée de petites formes de type gobelet, bol et écuelle. La céramique commune qui pourrait être associée à ce premier campaniforme est, en revanche, totalement attribuable aux groupes régionaux du Néolithique final. Aucune céramique commune campaniforme ne peut, en l'état actuel des recherches, être individualisée pour cette phase.

La notion du "package" campaniforme (Harrison 1980) est traditionnellement associée à ce Campaniforme ancien. En réalité dans le Sud-Est de la France, seule la sépulture de Forcalquier - La Fare qui associe gobelet campaniforme, vases d'accompagnement, poignard en cuivre et éléments de parure (les attributs de l'archer - armatures et brassard manquant) peut être rapprochée de cette notion. Les associations d'objets de Fontvieille Le Castellet et de Soyons - Le Serre d'Aurouze sont à rapporter à des phases plus évoluées du Campaniforme. II reste que le métal, présent dans chacun de ces " packages ", est rare dans le Sud-Est de la France et renforce l'idée du prestige ou au moins de 
l'importance de l'offrande constituée.

\section{Un Campaniforme funéraire}

Déterminer le statut de ce premier Campaniforme nécessite de répondre à la question de I'habitat campaniforme ancien. Un habitat suppose la présence de structures et de mobilier à caractère domestique. Aucun site ayant livré des vases de type ancien, actuellement connu, ne répond à ces critères. Les fragments de céramique pouvant être attribués au style maritime, découverts en contexte non funéraire, le sont sur des sites appartenant aux groupes locaux du Néolithique et ne sont représentés que par quelques fragments. Le contexte le plus fréquent pour ce type d'objet demeure funéraire. Cependant, le type de sépulture campaniforme reconnu à l'échelle européenne, la tombe individuelle répondant à des rites (position, orientation) précis et associant les objets du package, n'est attesté que par l'unique exemple de Forcalquier-La Fare.

Si des objets du Campaniforme ancien sont présents dans le Sud-Est de la France et presque exclusivement en contexte funéraire, ce n'est pas dans des sépultures d'un type spécifique mais au contraire dans les sépultures mégalithiques et dans les grottes sépulcrales. Ces types de sépultures livrent systématiquement du mobilier attribué aux groupes locaux du Néolithique final et sont traditionnels au sens où ils sont connus antérieurement à la présence des premiers objets campaniformes.

\section{Le phénomène campaniforme}

Pour appréhender la nature de ce premier campaniforme, il faut interpréter plusieurs constats :

- les objets campaniformes de cette phase sont d'origine allochtone à la région, même s'ils sont rapidement copiés sur place. En effet rien ne préfigure l'apparition des nouveautés de cette céramique dans les groupes présents antérieurement : morphologie, techniques et styles décoratifs, techniques de fabrication (emploi de chamotte);

- ils apparaissent simultanément en association avec différents groupes culturels indigènes, et bien au-delà des limites de la région considérée ;

- ils peuvent se trouver associés à des objets de tradition locale ;

- ils se trouvent en contexte funéraire soit, rarement, dans des tombes d'un type nouveau, soit, le plus souvent, dans les monuments traditionnels des cultures locales ;

- ils se trouvent très rarement en contexte d'habitat et ne constituent en ce cas jamais une culture matérielle à part entière mais ne représentent que quelques vases associés à de grandes séries de mobiliers locaux;

- ils peuvent être associés à des objets rares ou prestigieux comme les armes métalliques.

Cette phase (fig. 13), qui correspond au " vrai campaniforme", celui qui est à peu près identique sur une grande partie de l'Europe, demeure mal connue dans cette région et c'est sans doute ce qui en précise la nature : il s'agit d'un phénomène. Des objets, de tradition étrangère à la région apparaissent associés à des biens de valeur et dans des contextes précis, essentiellement funéraires. II s'agit presque exclusivement d'objets puisque aucune autre nouveauté importante ne peut être mise en évidence. La présence d'au moins une sépulture d'un type nouveau indique néanmoins que ce phénomène campaniforme n'est pas uniquement une diffusion d'objets mais aussi d'idées ou de personnes.

Qu'il s'agisse de la diffusion d'idées, croyances... ou de personnes, celle ci ne semble toucher qu'un nombre très réduit de personnes au sein des groupes locaux. II s'agit d'un phénomène, finalement assez marginal dans ses manifestations, qui ne peut correspondre à l'arrivée d'une population nouvelle. II n'est pas encore possible de préciser si ce phénomène a touché l'ensemble des groupes humains présents dans cette région. Le cas de Forcalquier - La Fare montre que ce premier campaniforme s'est inséré dans un contexte local attribué au groupe Rhône-Ouvèze qui correspond à la sphère d'influence du groupe languedocien de Fontbouisse. La question de la nature de la diffusion demeure posée. II peut s'agir 
d'échanges ou d'acquisitions de biens matériels ou plus probablement de la diffusion de personnes ou petits groupes véhiculant à la fois ces objets (gobelets maritimes) mais aussi leur technologie (permettant une rapide reproduction sur place) ainsi que certaines idées étrangères (sépulture individuelle).

\section{Le Campaniforme récent : la culture}

\section{Une culture matérielle et ses faciès}

La caractéristique principale de ce Campaniforme récent est l'existence d'une culture matérielle complète qui associe une céramique fine ornée ou non et une céramique commune spécifique. La céramique ornée (fig. 8) présente une grande variété qui peut être réduite à la distinction de faciès régionaux dont il n'est pas possible de préciser l'origine, qu'elle soit unique ou le résultat d'adaptations locales des objets diffusés antérieurement.

Le Sud-Est de la France défini pour notre étude (fig. 7) est donc l'aire d'extension de l'un de ces groupes régionaux : le groupe Rhodano-Provençal. Aux confins de cette région d'autres groupes régionaux sont présents, le groupe pyrénéen dans la partie occidentale du Gard et en Ardèche et le (ou les) faciès épimaritime(s) dans la moyenne vallée du Rhône et les Alpes. II n'y a pas de frontière nette entre ces groupes et des objets semblent se diffuser dans quelques cas dans les groupes voisins. La vallée du Rhône présente quant à elle, non une limite marquée, mais probablement une inversion progressive de proportion des décors incisés/estampés et des décors réalisés au peigne, selon un axe Sud-Nord. L'existence d'un faciès proprement Rhodano-Alpin n'est pas à exclure et devra être vérifiée dans l'avenir. La céramique commune associée aux vases ornés du groupe Rhodano-Provençal est, contrairement à celle de la phase précédente, spécifique. Elle appartient à un ensemble défini, Rhodano-Rhénan, et se rencontre effectivement dans l'axe Rhodano-Rhénan mais aussi dans tout le Midi de la France avec quelques diffusions plus lointaines (Normandie, Italie...) Cette céramique commune pose le problème d'être identique pour les différents faciès régionaux de céramique ornée. Si elle n'est pas présente dans la phase antérieure du Campaniforme, il faut s'interroger sur la possible origine commune ou les contacts préférentiels des différents faciès régionaux de la phase récente.

\section{Une variété de contextes}

Les groupes régionaux présentent d'autres aspects qui les distinguent du Campaniforme ancien. Les contextes de découvertes sont en effet partiellement différents. Le Campaniforme garde une grande importance pour le domaine funéraire. De très nombreuses sépultures, presque exclusivement collectives livrent des vases décorés ou même des assemblages à rapprocher du " package ". Il semble même que le dépôt de céramique ornée dans les sépultures mégalithiques devienne un rite important qui n'était que peu pratiqué dans les phases pré-campaniformes du Néolithique final où les dépôts funéraires étaient principalement constitués d'outillage lithique et d'éléments de parure. Le Campaniforme récent est aussi toujours présent sur des sites attribués aux groupes locaux du Néolithique final. II présente dans ce cas plusieurs types d'association. II existe des sites du Néolithique final avec un secteur ou une unité d'habitation qui livrent des objets campaniformes et d'autres sites indigènes où le Campaniforme n'est représenté que par quelques vases ornés et, comme à la période précédente, aucune céramique domestique spécifique.

$\mathrm{Ce}$ qui semble réellement nouveau est la présence de réels habitats campaniformes associant les différents éléments d'une culture matérielle spécifique. Ces sites présentent une topographie et des dimensions variées. II ne semble pas y avoir une architecture spécifique et les structures connues sont adaptées aux contextes géographiques et géologiques locaux.

\section{La culture campaniforme régionale et ses relations avec les cultures locales}


Pour cette phase, une géographie particulière de l'implantation et de la nature des sites pourrait être montrée (Lemercier à paraître). II semble, en effet, y avoir une distinction entre les sites proprement campaniformes et les sites du Néolithique final qui livrent quelques objets campaniformes. Dans la vallée du Rhône ou le Gard rhodanien, les sites proprement campaniformes sont des sites de plaine pouvant être relativement importants. En Provence, en revanche, ces sites campaniformes " purs " semblent implantés systématiquement dans des situations topographiques particulières : il s'agit de sites perchés ou cachés et de surface réduite. Dans cette région, de nombreux sites de plaine, attribués au Néolithique final, livrent quelques objets campaniformes (Courtin, D'Anna et A.H.C.L. 1985).

Ces sites du Néolithique final qui livrent des vases campaniformes ornés sans la présence de céramique commune spécifique doivent, selon nous, être considérés comme homogènes et contemporains des sites campaniformes purs qui livrent une céramique décorée identique. Leur interprétation systématique en terme de remaniements et de réoccupations ne semble pas convaincante.

II semble donc que cette phase voit le développement d'une réelle culture campaniforme, bien distincte de la nature du phénomène campaniforme antérieur. Certains (Salanova $1997,1998)$ considèrent que cette phase ne correspond plus, à proprement parler, à du " vrai " Campaniforme. II semble néanmoins que celle-ci résulte de la réaction de certaines cultures locales à la diffusion du premier Campaniforme dont la tradition est évidente et doit donc être conservée dans la terminologie.

Cette culture Campaniforme (fig. 13) ne semble pas remplacer, au moins dans un premier temps, les cultures locales du Néolithique final. Deux interprétations de ces remarques sont possibles : Une interprétation diachronique suppose que la différence entre les sites " à campaniformes " et les sites proprement campaniformes correspondent à deux phases successives. La première phase correspond à l'assimilation de la céramique décorée Campaniforme par les cultures locales qui l'adaptent en créant le style Rhodano-Provençal. Ces groupes conservent leur fond commun céramique et seule la céramique ornée est nouvelle. Une seconde phase correspond à la diffusion de la céramique commune du complexe Rhodano-Rhénan qui remplace dans le groupe Rhodano-Provençal, la traditionnelle céramique commune du Néolithique final donnant naissance aux sites proprement campaniformes.

Une interprétation synchronique demeure néanmoins possible. Elle suppose que si la culture Campaniforme s'est développée à partir d'une culture locale du Néolithique final qui a assimilé le phénomène campaniforme, cela s'est produit soit à l'extérieur de cette région, soit à partir de l'une des cultures locales présentes sans faire disparaître les autres. Coexisteraient alors dans une même région des groupes campaniformes et des groupes du Néolithique final dont certains pourraient avoir la possession de vases décorés du style Rhodano-Provençal acquis par des systèmes d'échanges entre ces cultures.

Si ces deux interprétations demeurent conjecturales, il est possible de considérer ces groupes régionaux du Campaniforme récent comme des cultures archéologiques au sens propre. II s'agit ici d'une réaction au niveau régional à la diffusion du phénomène campaniforme. Mieux comprendre les modalités de cette adaptation ou assimilation pourrait peut-être contribuer à mieux comprendre la nature du phénomène diffusé initialement.

\section{Le Bronze ancien Barbelé : la tradition}

\section{Un mobilier de tradition campaniforme et des apports nouveaux}

Les céramiques " épicampaniformes " ou du Bronze ancien à décor barbelé (fig. 10) ont la particularité d'associer des éléments relatifs au Campaniforme et d'autres totalement nouveaux.

Ce sont les décors, de par leur technique, les motifs réalisés et leur disposition, qui évoquent une tradition campaniforme possible. Outre les décors barbelés, un grand nombre de décors incisés présentent des motifs de quadrillages, bien connus dans le style Rhodano-Provençal, et de plus rares décors réalisés au peigne, dans une tradition pleinement campaniforme 
peuvent y être associés. La disposition majoritaire de ces motifs en bandes horizontales fait référence au Campaniforme et la présence de décors en bandes verticales ou en cadres pourrait être interprétée en terme d'évolution à partir du Campaniforme récent où ils apparaissent. Les formes céramiques, en revanche et à de rares exceptions près, se distinguent nettement de la tradition campaniforme. Si certains vases présentent des formes de gobelets, de bols et d'écuelles connues dans la typologie des campaniformes décorés, la plupart d'entre eux serait plutôt à rapprocher de la céramique commune spécifique du Campaniforme du complexe Rhodano-Rhénan ou de la Begleitkeramik comme les tasses ansées, les pichets... D'autres encore comme les urnes et jarres biconiques semblent totalement déconnectées des traditions.

Les objets en bronze font aussi leur apparition avec ces séries. S'ils restent très rares, ils témoignent néanmoins de réels apports nouveaux dont la composante rhodanienne semble toujours importante.

\section{Les questions d'origine et de faciès}

La question de l'origine de la céramique à décor barbelé demeure non résolue. La répartition de ce type de mobilier dépasse de beaucoup le cadre régional du Sud-Est de la France.

Certains ont voulu identifier des faciès distincts comme le style Camp de Laure en Provence et le style Rocher-du-Causse en Languedoc et reconnaître des évolutions sur place à partir des groupes du Campaniforme récent. II semble actuellement que ces distinctions ne reposent que sur des problèmes de description et d'identification des décors (Lemercier, Salanova, D'Anna et Gutherz [dir.] en préparation).

\section{Une tradition campaniforme}

Malgré cette méconnaissance, qui nécessitera des recherches dans l'avenir, il est possible de reconnaître dans ces groupes la présence d'une réelle tradition campaniforme.

Outre les remarques concernant les productions céramiques, d'autres aspects vont dans ce sens. Les données funéraires continuent à montrer une remarquable continuité entre le Campaniforme récent et le Bronze ancien à décor barbelé. De même, la répartition des sites de cette phase semble avoir une forte relation avec la répartition des sites de la phase antérieure, avec une concentration remarquable au débouché de la vallée du Rhône.

Néanmoins, il est évident qu'il ne s'agit pas réellement d'un Epicampaniforme. Outre une typologie (formes céramiques) et une technologie (bronze) nouvelles et probablement d'origine extérieure à la région, la nature des sites semble, elle aussi, changer avec une certaine généralisation des occupations d'éperons et de sites perchés (fig. 9).

Le Bronze ancien barbelé est sans doute pleinement une phase du Bronze ancien, même si des traditions (fig. 13) campaniformes y perdurent pendant un temps.

\section{LE ROLE DU CAMPANIFORME AU IIP MILLÉNAIRE}

Les phases et les statuts successifs du Campaniforme étant individualisés, et même si de nombreuses questions devront encore être précisées, il devient plus facile de s'interroger sur le rôle qu'il a pu avoir dans le déroulement du Néolithique final.

\section{Le Campaniforme ancien : diffusions de techniques ou de symboles ?}

\section{Le Campaniforme et la métallurgie}

La diffusion de la métallurgie, souvent évoquée pour expliquer le phénomène campaniforme ne pourrait être le moteur de la première présence campaniforme dans le Midi de la France. II est, en effet, maintenant connu que la métallurgie dans cette région est nettement antérieure à l'apparition du Campaniforme (Ambert 1996 et à paraître).

Mais cette idée n'est, pour le moment, validée qu'en Languedoc. Le cas du Sud-Est demeure 
moins clair, aucune trace évidente d'activité métallurgique antérieure à la diffusion campaniforme n'étant attestée. Ainsi Jean Courtin pouvait même écrire que la presque totalité des objets en cuivre de Provence était à rapporter au Campaniforme (Courtin 1974). Rien ne semble, pour le Sud-Est de la France, infirmer sérieusement l'idée d'une association possible entre la diffusion du Campaniforme et celle du métal. L'existence d'une métallurgie antérieure au Campaniforme en Languedoc n'interdit pas l'arrivée de producteurs ou colporteurs d'objets métalliques. Cette concurrence pourrait même expliquer la curieuse rareté des sépultures à mobilier campaniforme dans la région du Gard oriental et de l'Hérault.

Cette idée suppose l'existence d'une production de métal propre au Campaniforme, qu'il s'agisse de la diffusion d'une technique ou de produits finis. Une métallurgie campaniforme ne semble pas avoir été reconnue, jusqu'à maintenant, dans le Midi de la France, mais elle demeure possible.

\section{Le Campaniforme et des techniques méconnues}

D'autres techniques ou d'autres objets peuvent ils être liés à la diffusion campaniforme ? La question a été posée à plusieurs reprises, mais aucune réponse ne semble réellement convaincante. A part la métallurgie, aucun des objets associés au Campaniforme ne semble faire appel à des techniques nouvelles ou sophistiquées. L'industrie lithique ne semble pas se démarquer beaucoup des productions des groupes du Néolithique final même avec la présence de quelques objets typologiquement spécifiques. Un tissage campaniforme a été évoqué, en liaison avec certaines idées sur le peu d'investissement technique de l'habitat campaniforme supposant un mode de vie moins sédentaire lié à une activité prépondérante d'élevage. Cette hypothèse reste très mal étayée en l'état actuel des connaissances.

La " fameuse " céramique campaniforme

La seule réelle diffusion correspondant au phénomène campaniforme est celle de la céramique, mais rien ne permet d'en préciser la fonction réelle. Le vase campaniforme est souvent considéré comme un symbole. En effet, sa rareté, sa qualité et son usage funéraire en association avec des objets de prestige (les rares armes métalliques) sont remarquables. Mais intrinsèquement sa fonction symbolique demeure conjecturale et pourrait même être une valeur ajoutée, déconnectée de la volonté de ses fabricants et liée à sa rareté pour l'utilisateur.

Le vase campaniforme est aussi, et peut-être avant tout, un contenant. Mais il n'est pas possible d'établir un lien avec un contenu spécifique. Si ce lien devait exister, il correspondrait non à la diffusion d'un produit, le vase campaniforme ne pouvant être interprété comme un contenant pratique à déplacer sur de longue distance, mais à l'usage d'un produit. Rien ne permet d'étayer ces hypothèses.

Le vase campaniforme pourrait aussi être interprété comme un " savoir faire " céramique. Plusieurs remarques vont dans ce sens. Les études pétrographiques de Fabien Convertini ont montré la spécificité de la céramique campaniforme pour le Midi de la France, avec l'emploi de chamotte. Les vases sont très rapidement produits sur place et il ne s'agit pas de simples copies, puisque ces productions utilisent la technique campaniforme (Convertini 1996). L'utilisation de ces techniques pour la production de céramiques indigènes (comme le vase à décor Fontbouisse de Donzère - La Chauve Souris) est maintenant attestée (Convertini à paraître). Enfin, la réutilisation de vases campani-formes en chamotte dans la fabrication de nouveaux vases (Convertini et Othenin-Girard 1997) pourrait indiquer une valeur particulière accordée à cette céramique dans sa propre reproduction. Si le phénomène campaniforme ancien est lié à la diffusion d'une technique particulière, la plus remarquable est donc celle de la céramique elle-même. II n'est cependant pas possible d'écarter la possibilité d'une liaison avec la diffusion d'objets métalliques, si ce n'est même de leur technique de fabrication.

\section{De la diffusion à l'intégration : des changements sociaux et idéologiques ?}




\section{Le Campaniforme et la mort}

Pour la phase ancienne du Campaniforme, le caractère particulier du mobilier campaniforme et de son contexte funéraire sont évidents. Qu'il s'agisse d'un réel symbole ou du simple prestige de la détention d'objets rares ou de qualité, le rôle du vase campaniforme n'est pas celui accordé généralement à la céramique.

Avec le développement des groupes régionaux, le vase campaniforme, associé à d'autres contextes probablement domestiques, perd ce caractère particulier. Mais il continue à être utilisé en contexte funéraire et semble s'ajouter aux rites traditionnels du Néolithique final. $\mathrm{Ce}$ campaniforme ne semble cependant pas provoquer de changements radicaux dans les modes funéraires du Néolithique final. II ne constitue sans doute qu'un élément de plus dans le statut particulier accordé à certains morts pour leurs offrandes funéraires. La sépulture de Forcalquier - La Fare est l'exception qui montre que les sociétés choisissent de conserver pour l'essentiel leurs traditions d'inhumations en monuments collectifs.

\section{Le mode de vie des groupes campaniformes récents}

II n'est possible d'envisager un " mode de vie campaniforme" que pour la seule phase récente. Mais les connaissances, en ce domaine, demeurent très limitées. L'investissement technique lié à l'habitat campaniforme est considéré comme peu important en Languedoc et en Provence. En réalité, cette observation n'est fondée que sur une comparaison avec les très belles architectures du groupe de Fontbouisse et des groupes périphériques qui sont aussi inconnues dans les autres groupes du Néolithique final. II convient en fait de bien distinguer les deux phases du Campaniforme.

Le phénomène campaniforme en raison de son statut ne connaît pas de sites qui lui soient propres. En réalité, il est très probable que des objets campaniformes ancien se trouvent dans les cabanes Fontbouisse, non en réoccupation mais en association. La phase de la culture campaniforme montre en revanche un certain nombre de sites d'habitat qui n'ont été que rarement fouillés. Les sites campaniformes du Gard montrent d'ailleurs des structures qui sont difficilement interprétables mais qui existent et les sites évalués dans la vallée du Rhône montrent probablement des constructions sur poteaux et non à murs de pierre, ce qui est expliqué par le contexte géologique. Rien n'indique réellement, surtout pour la rive gauche du Rhône, un moindre investissement technique lié à I'habitat pour le Campaniforme par rapport aux cultures antérieures.

Le faible nombre de sites campaniformes fouillés et étudiés exhaustivement ne permet pas de s'interroger correctement sur une éventuelle économie particulière pour le Campaniforme. L'hypothèse d'une société essentiellement pastorale, évoquée dans d'autres régions, ne peut être sérieusement envisagée pour le Sud-Est de la France avec la mise en évidence de sites de plaine implantés sur les meilleures terres agricoles de la vallée du Rhône.

\section{La société campaniforme régionale}

La question démographique du Campaniforme pose de nombreux problèmes. Des comparaisons entre le grand nombre de sites du Néolithique final et les rares sites campaniformes ne peuvent être validées. En effet, la courte durée du groupe RhodanoProvençal est très probable.

Rien ne permet non plus d'aborder, pour la phase récente, les questions d'une éventuelle hiérarchisation spécifique de la société. S'il demeure probable que les divers éléments du "package campaniforme" mis au jour dans les sépultures collectives sont relatifs au dépôt d'un unique individu, il demeure difficile d'accorder pour cette phase un caractère de prestige au vase campaniforme.

Le nombre de vases décorés, pour cette phase récente, est tel qu'il ne permet plus de lui accorder une idée de prestige ou de symbole. II s'agit pleinement d'une culture matérielle, et le dépôt de vases ornés dans les tombes ne peut être considéré que comme un élément mineur lié à un rite plutôt qu'à un symbole. Le prestige et la qualité particulière de l'individu 
inhumé sont alors à rechercher dans la présence d'autres éléments qui ne sont pas devenus plus courants qu'à la phase antérieure (armes et parures métalliques).

\section{Le Campaniforme entre aboutissement et transition}

\section{Des changements amorcés anciennement}

L'essor démographique du Néolithique final est connu même si ses causes ne sont pas encore précisées. Cette fin du Néolithique semble être, dans le Sud-Est de la France, un monde densément peuplé et occupé. Les sites correspondent probablement à des fonctions spécifiques et hiérarchisées (villages principaux, fermes, haltes de chasse, sites de rassemblement défensifs ou cultuels...)

Le monumentalisme en contexte d'habitat semble peu important au Néolithique moyen en l'absence de grands sites à fossés comme ceux connus dans d'autres régions même si les données très récentes concernant des complexes importants comme Montélimar - Le Gournier (fouille A. Beeching) pourraient bientôt infirmer cette hypothèse. Ce monumentalisme connaît, quoi qu'il en soit, un grand développement au cours du Ille millénaire avec les sites à enceintes constituées de murs ou de fossés. L'investissement accordé à ces constructions semble important et correspond au moins autant, sinon plus, à une volonté d'ostentation qu'à de réelles préoccupations défensives. Le soin accordé à la construction de sépultures collectives, parfois exceptionnelles, est de la même nature, même si son origine est probablement plus anciennement enracinée dès la fin du Néolithique moyen. La diffusion assez précoce d'objets métalliques qui se trouvent être le plus souvent des parures et dans une moindre mesure des armes plutôt que des outils s'inscrit dans la même idée.

S'il reste difficile déjuger de la hiérarchisation de cette société, le développement de tous ces signes extérieurs de richesse ou de puissance semble marquer à la fois les groupes humains et les individus.

\section{Le Campaniforme comme conséquence et comme cause}

Replacé dans ce contexte de mutations importantes des sociétés au cours du IIP millénaire, le Campaniforme peut être considéré selon les domaines et les régions comme la cause ou l'effet des changements. Le Campaniforme peut être compris comme une conséquence de son époque. André D'Anna a pu ainsi écrire : "Le Campaniforme ne s'est probablement pas diffusé spontanément en Provence mais il y a répondu, en quelque sorte, à une demande. " (D'Anna 1995a p. 325). En effet, le phénomène Campaniforme semble, dans cette région, bien s'inscrire dans son époque. II ne constituerait alors qu'un élément de plus, venu s'ajouter à une société déjà hiérarchisée et avide d'objets de prestige. À l'opposé, et malgré l'antériorité probable de certains changements, le Campaniforme pourrait être interprété comme un vecteur de diffusion de certaines techniques et même de certaines idées. Même si la situation est différente en Languedoc, et considérant la rareté des objets métalliques dans le Sud-Est pré-campaniforme, la diffusion du Campaniforme semble bien liée à celle d'objets métalliques dans cette région. Il en va de même pour la sépulture individuelle et ses rites spécifiques, dans le domaine des idées. Ces deux interprétations ne sont pas contradictoires et peuvent être combinées. Ainsi, la diffusion du Campaniforme, sans doute liée à un paroxysme des compétitions sociales, a pu amener avec elle des techniques et des idées étrangères aux sociétés réceptrices.

Vers des âges " encore " obscurs : le Bronze ancien

Le rôle du Campaniforme est aussi envisagé dans la transition du Néolithique final au Bronze ancien. La question est de savoir ce qui dans les différents aspects du Campaniforme prépare ou préfigure l'âge du Bronze ancien.

Le premier Bronze ancien régional peut être perçu comme le résultat d'une forte tradition 
Campaniforme et de nouveaux apports techniques et stylistiques. S'il est difficile de faire la part en proportion de ces traditions et de ces nouveautés, il l'est plus encore de déterminer le caractère uniquement allochtone de ces dernières.

II s'agit, lorsque le mobilier archéologique est observé et comparé aux productions antérieures, d'ensembles tout à fait différents du Campaniforme précédent. Et pourtant, l'analyse stylistique des formes et des décors ainsi que la géographie des sites permettent de retrouver l'importance de la tradition Campaniforme. Le développement du Bronze ancien, avec ses parts étrangères - Culture du Rhône - (Gallay 1996) et indigènes (Gutherz 1995, Vital 1996) est encore trop méconnu pour analyser les modalités de cette transition et de la fin du Campaniforme.

\section{CONCLUSIONS}

Les trois places et les trois statuts du Campaniforme (fig. 13)

Dans le cadre régional défini, le Campaniforme correspond au cycle complet de développement d'une culture. II s'agit dans un premier temps de la diffusion d'objets étrangers utilisés à des fins particulières et rapidement reproduits sur place. Ils sont probablement associés à la diffusion d'autres objets et d'idées extérieures aux traditions locales. Ce phénomène s'inscrit bien dans le contexte local, concernant peu d'individus mais d'une façon assez importante pour que la culture matérielle indigène s'en trouve rapidement modifiée. Ainsi apparaissent, probablement très rapidement, des cultures campaniformes régionales, selon des modalités qu'il reste à préciser. Ces cultures campaniformes constituent un ensemble autonome, partageant une céramique commune et s'identifiant par des faciès de céramique ornée. Elles entretiennent probablement des relations d'échanges avec les cultures locales du Néolithique final qui semblent perdurer. Le Campaniforme perdure ensuite, dans le Sud-Est de la France, tout en intégrant des composantes nouvelles, mais il ne s'agit plus alors que d'une tradition. II s'agit bien, en fait, d'une culture nouvelle. La disparition de la tradition campaniforme dans les phases plus avancées du Bronze ancien demeure mal datée.

\section{De l'approche régionale aux questions générales, le rôle du Campaniforme}

En raison de la variabilité de ses manifestations et de sa nature dans le temps et dans l'espace, le Campaniforme est difficile à appréhender comme un tout. L'approche régionale permet cependant de considérer cette variabilité dans une perspective diachronique et d'aboutir à une image à la fois plus dynamique et plus simple d'un complexe trop hétérogène dans sa globalité. Cette approche ne permet pas de considérer le rôle du Campaniforme à l'échelle européenne, mais peut permettre de mieux appréhender la nature du phénomène pour une région donnée.

Le phénomène campaniforme n'ayant pas entraîné les mêmes réactions culturelles dans toutes les régions de sa diffusion, il ne semble pas évident, non plus, qu'il corresponde à une nature unique et identique, dans toutes les régions concernées.

Ainsi, le campaniforme peut être interprété comme vecteur de diffusion d'idées ou d'objets nouveaux et en même temps comme répondant à l'évolution de sociétés de plus en plus complexes, en quête de symboles ou de marqueurs sociaux.

\section{Le Campaniforme et l'entrée dans l'Histoire}

La difficulté à appréhender le Campaniforme comme un ensemble est la conséquence de la multiplicité des liens qui unissent la diversité des faits archéologiques observés. Seule l'approche régionale permet d'établir des scénarios qui peuvent s'approcher d'une certaine réalité, au moins au sens de leur complexité. En ce sens, comme l'a proposé Jean Guilaine pour le Néolithique, il semble possible, particulièrement pour cette période de mutation importante de la société qu'est le Ille millénaire, de parler d'Histoire, non au sens traditionnel 
du terme consacrant la place de l'écrit, mais parce que les événements qui participent et gouvernent l'ensemble de ces transformations sont des événements d'ordre historique (commerce, recherche de gloire et de puissance, guerres, alliances, colonisations...), prémisses de ceux connus par les récits de la Grèce archaïque.

\section{RÉFÉRENCES BIBLIOGRAPHIQUES}

AMBERT P. (1996) - Cabrières - Hérault et le contexte régional du développement de la première métallurgie du cuivre en France (Ille millénaire av. J.-C.), Archéologie en Languedoc, $\mathrm{n}^{\circ} 20,69 \mathrm{p}$.

AMBERT P. (à paraître) - La place de la métallurgie campaniforme dans la première métallurgie française, in: Actes du colloque international "Bell Beakers Today", Riva del Garda (Trento, Italie), mai 1998, à paraître.

BARGE-MAHIEU H. (dir.) (1992) - Le Campaniforme dans le Midi de la France, origine et identité culturelle, catal. d'expo., Marseille, Éd. E.P.A., 96 p.

BESSE M. (1996) - Le Campaniforme en France, Analyse de la céramique d'accompagnement, Oxford, British Archaeological Report, International Séries, 635, 56 p., 115 fig., 26 pl.

CONVERTINI F. (1996) - Production et signification de la céramique campaniforme à la fin du 3e millénaire av. J.-C. dans le Sud et le Centre-Ouest de la France et en Suisse occidentale, Oxford, British Archaeological Report, International Series, 656, 362 p.

CONVERTINI F. (à paraître) - Production de la céramique campaniforme dans l'axe RhinRhône, in : Actes du colloque international "Bell Beakers Today ", Riva del Garda (Trento, Italie), mai 1998, à paraître.

CONVERTINI F. et OTHENIN-GIRARD B. (1997) - Analyse techno-culturelle, in : B. OtheninGirard (dir.), Le Campaniforme d'Alle, Noir Bois, Cahiers d'Archéologie Jurassienne, $\mathrm{n}^{\circ} 7$, p. 85-91.

COURTIN J. (1967) - La culture du vase campaniforme en Provence, note préliminaire, Cahiers Ligures de Préhistoire et d'Archéologie, 16, p. 27-36.

COURTIN J. (1974) - Le Néolithique de la Provence, Paris, Klincksieck, Mém. de la S.P.F., t. $11,355 \mathrm{p}$.

COURTIN J., D'ANNA A. et A.H.C.L. (1985) - La céramique campaniforme du site des Lauzières, Lourmarin, Vaucluse, Bull. Archéol. de Provence, 15, p. 5-9.

D'ANNA A. (1995a) - La fin du Néolithique dans le Sud-Est de la France, in: R. Chenorkian (dir), L'Homme méditerranéen, Mélanges offerts à Gabriel Camps, Aix-en-Provence, Public, de I'Univ. de Provence, L.A.P.M.O., p. 299-333.

D'ANNA A. (1995b) - Le Néolithique final en Provence, in : J.-L. Voruz (dir.), Chronologies néolithiques : de 6000 à 2000 avant notre ère dans le Bassin Rhodanien, Actes des Rencontres néolithiques Rhône-Alpes, Ambérieu-en-Bugey, septembre 1992, Ambérieu-en-Bugey, Document du Département d'Anthropologie et d'Ecologie de I'Univ. de Genève, 20, Éd. de la Soc. Préh. Rhodanienne, p. 265-286.

DEL CASTILLO YURRITA A. (1928) - La cultura del vaso campaniforme (su origen y su extension en Europa), Barcelona, Universitad de Barcelona, 216 p., 208 pl. 
GALLAY A. (1986) - Autonomie du Campaniforme rhodano-rhénan : la question de la céramique domestique, in : J.-P. Démoule, J. Guilaine (dir.) : Le néolithique de la France, Hommage à G. Bailloud, Paris, Picard, p. 431-446.

GALLAY A. (1996) - Le concept de Culture du Rhône : repères pour un historique, in : C. Mordant et O. Gaiffe (dir.), Cultures et Sociétés du Bronze ancien en Europe, Actes du 117e Congrès National des Sociétés Savantes (Clermont-Ferrand 1992), Paris, Éd. du C.T.H.S., p. 271-286.

GUILAINE J. (1976) - La civilisation des gobelets campaniformes dans la France méridionale, in : . Guilaine (dir.) La Civilisation des vases campaniformes, IXe Congrès de I'U.I.S.P.P., Colloque XXIV, Nice $1976^{\wedge}$ p. 197-213, 2 pl.

GUILAINE J., CLAUSTRE F., LEMERCIER 0 . et SABATIER P. (à paraître) Campaniformes et environnement culturel en France méditerranéenne, in : Actes $d u$ colloque international "Bell Beakers Today ", Riva del Garda (Trento, Italie), mai 1998, à paraître.

GUTHERZ X. (1984) - Les cultures du Néolithique récent et final en Languedoc oriental, Thèse de doctorat de $3 e$ cycle sous la direction de $M$. le $\operatorname{Pr} G$. Camps, L.A.P.E.M.O./Université de Provence, Aix-en-Provence, 2 vol., 375 p., 256 pl.

GUTHERZ X. (1995) - Quelques réflexions sur l'origine et la chronologie du Bronze ancien dans le Sud-Est de la France, in : R. Chenorkian (dir.), L'Homme méditerranéen. Mélanges offerts à Gabriel Camps, Aix-en-Provence, Publications de I'Univ. de Provence, L.A.P.M.O., p. 375-401.

HARRISON R.J. (1980)- The Beaker Folk, Copper Age archaeology in Western Europe, London, Thames and Hudson Ltd, $176 \mathrm{p}$.

LEMERCIER O. (1996) - La céramique des niveaux campaniformes des terrasses I et XI du site du Col Sainte Anne (Simiane-Collongue - Bouches-du-Rhône), études spatiale et culturelle, et le Campaniforme en Provence, Mém. de Maîtrise sous la dir. de M. le Professeur R. Chenorkian, L.A.P.M.O./Univ. De Provence, Aix-en-Provence, 2 vol., 204 p., 39 pi., 338 fiches.

LEMERCIER O. (1997a) - Le phénomène campaniforme et la transition du Néolithique final au Bronze ancien dans le sud-est de la France, Mém. de D.E.A. sous la dir. de M. le Pr R. Chenorkian, L.A.P.M.O./Univ. de Provence, Aix-en-Provence, 155 p., 18 pl.

LEMERCIER O. (1997b) - Le Campaniforme dans la moyenne et basse vallée du Rhône, in : L'énigmatique civilisation campaniforme, Archéologia, hors-série, 9, déc. 1997-janv. 1998, p. 30-34.

LEMERCIER O. (1998) - The Bell Beaker phenomenon in thé Southeast of France : The state of research and preliminary remarks about the TGV-excavations and some other sites of thé Provence, in : M. Benz, S. Van Willigen (éd.), Some New approaches lo The Bell Beaker Phenomenon, Lost Paradise...?, Procee-dings of the 2nd Meeting of the "Association Archéologie et Gobelets", Feldberg (Germany), 18lh-20lh avril 1997, British Archeological Report, International Séries, 690, p. 23-41.

LEMERCIER O. (à paraître) - The Bell Beaker phenomenon in the Southeast of France : an historical geography ? in : Actes du colloque international "Bell Beakers Today", Riva del Garda (Trente, Italie), mai 1998, à paraître. 
LEMERCIER O., DÙH P., LOIRAT D., MELLONY P., PELLISSIER M., SERIS D., TCHEREMISSINOFF Y. et BERGER J.-F. (à paraître) - Les Juilléras (Mondragon Vaucluse) site d'habitat et funéraire du Néolithique récent, Néolithique final, Campaniforme - Bronze ancien et Bronze final Ilb : premiers résultats, in: Actes des Rencontres Méridionales de Préhistoire Récente, deuxième Session, Arles, novembre 1996, Antibes, Éd. A.P.D.C.A.

LEMERCIER O. (en préparation) - Espaces culturels et territoires : Approches spatiales des groupes campaniformes récents dans le Sud-Est de la France, Rencontres Méridionales de Préhistoire Récente, Troisième session, Toulouse, 1998, en préparation.

LEMERCIER O., SALANOVA L., D'ANNA A. et GUTHERZ X. (dir.) (en préparation) - Le Bronze ancien barbelé dans le Midi de la France et les régions voisines, en préparation.

LEMERCIER 0., MULLER A. et BOUVILLE C. (1996) - Le site Néolithique final/Chalcolithique et la sépulture campaniforme de La Fare (Forcalquier - Alpesde-Haute-Provence - France) Premiers résultats, in : XIIle Congrès de I'Union Internationale des Sciences Préhistoriques et Protohistoriques, Forli 1996, Section 10 : Âge du cuivre du Proche Orient et de l'Europe, Résumés des Communications, Forli, Éditions A.B.A.C.O., p. 290.

MULLER A. et D'ANNA A. (1986) - Le gisement de plein air chalcolithique de la Plaine-desBlancs à Courthézon, Vaucluse, Bull. de la S.P.F., T. 83, n 10-12, p. 470-483.

MULLER A. et LEMERCIER O. (1994) - Le site néolithique final/ chalcolithique de La Fare à Forcalquier (Alpes-de-Haute-Provence), Bull. de la S.P.F., T. 91, nº 3, p. 187-189.

MULLER A., LEMERCIER O. et BOUVILLE C. (1997) - Une sépulture individuelle à Forcalquier - La Fare (Alpes-de-Haute-Provence), in: L'énigmatique civilisation campaniforme, Archéologia, hors-série, 9 déc. 1997-janv. 1998, p. 35.

MULLER A. et LEMERCIER O. (dir.) (en préparation) - La sépulture à vase campaniforme de Forcalquier - La Fare (Alpes-de-Haute-Provence), en préparation.

SALANOVA L. (1997a) - Des cloches et des coquillages... Fabrication et ornementation des vases campaniformes en France, Thèse de nouveau Doctorat, Univ. de Paris I.

SALANOVA L. (1997b) - Le Campaniforme en France et dans les îles anglo-normandes : caractérisation des productions céramiques, Bull. de la S.P.F., T. 94, n 2, p. 259264.

SALANOVA L. (1998) - A long way to go... : The bell beaker chrono-logy in France, in : M. Benz, S. van Willigen (éd.), Some New approaches to The Bell Beaker Phenomenon, Lost Paradise...?, Proceedings of thé 2nd Meeting of the " Association Archéologie et Gobelets", Feldberg (Germany), 18-20 avril 1997, British Archaeological Report, International Series, 690 , p. 1-13.

TREINEN-CLAUSTRE F. (1989) - L'évolution des campaniformes, in : J.-P. Mohen (dir.), Le Temps de la Préhistoire, T. 1, Paris, S.P.F./Archéologia, p. 409-412.

VAQUER J. (1998) - Le Mourral, Trèbes (Aude) A fortified languedocian late neolithic site reoccupied by bell beakers, in : M. Benz, S. van Willigen (éd.), Some New approaches to The Bell Beaker Phenomenon, Lost Paradise...?, Proceedings of the 
LEMERCIER O. (1998) - Phénomène, culture et tradition : statuts et rôles du Campaniforme au Ille millénaire dans le sud-est de la France, Bulletin de la Société Préhistorique Française, tome 95, n³ 1998, p. 365-382.

2"' Meeting of the "Association Archéologie et Gobelets", Feldberg (Germany), 18'"20"' avril 1997, British Archaeological Report, International Series, 690, p. 15-21.

VITAL J. (1996) - État des travaux sur l'Âge du Bronze ancien médio-rhodanien, in : C. Mordant et O. Gaiffe (dir.), Cultures et Sociétés du Bronze ancien en Europe, Actes du 117" Congrès National des Sociétés Savantes (Clermont-Ferrand 1992), Paris, éd. du C.T.H.S., p. 325-338.

\section{Olivier LEMERCIER}

Laboratoire d'Anthropologie et de Préhistoire des Pays de la Méditerranée Occidentale (L.A.P.M.O.)

Maison Méditerranéenne

des Sciences de l'Homme

5, rue du Château de l'Horloge,

B.P. 647 - F-13094 Aix-en-Provence Cedex 2 


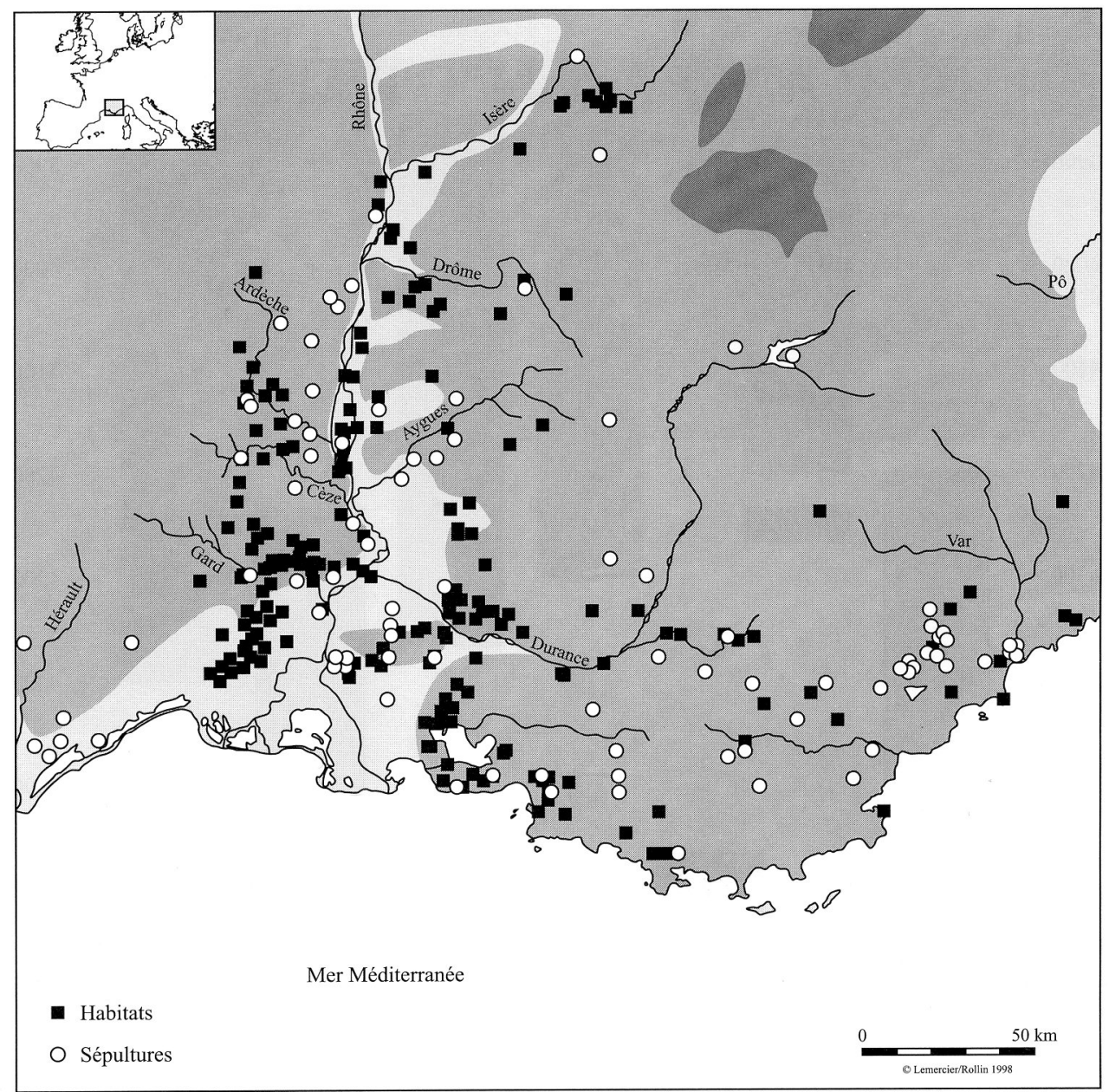

Fig. 1. - Carte de répartition schématique des sites et sépultures à mobilier campaniforme dans le Sud-Est de la France. 


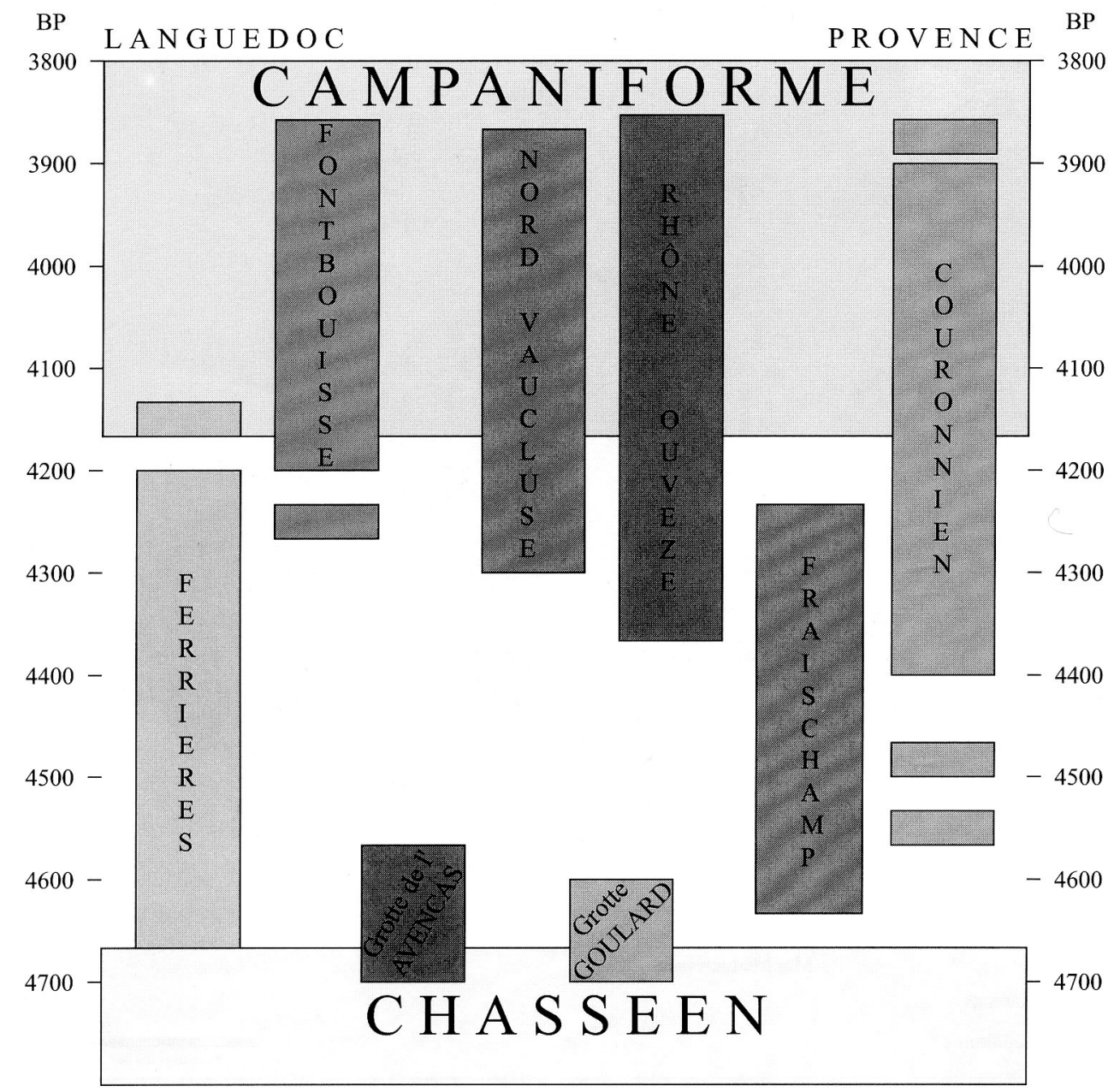

Fig. 2. - Place chronologique des groupes culturels du Néolithique final dans le Sud-Est de la France, d'après A. D'Anna (1995) simplifié. 


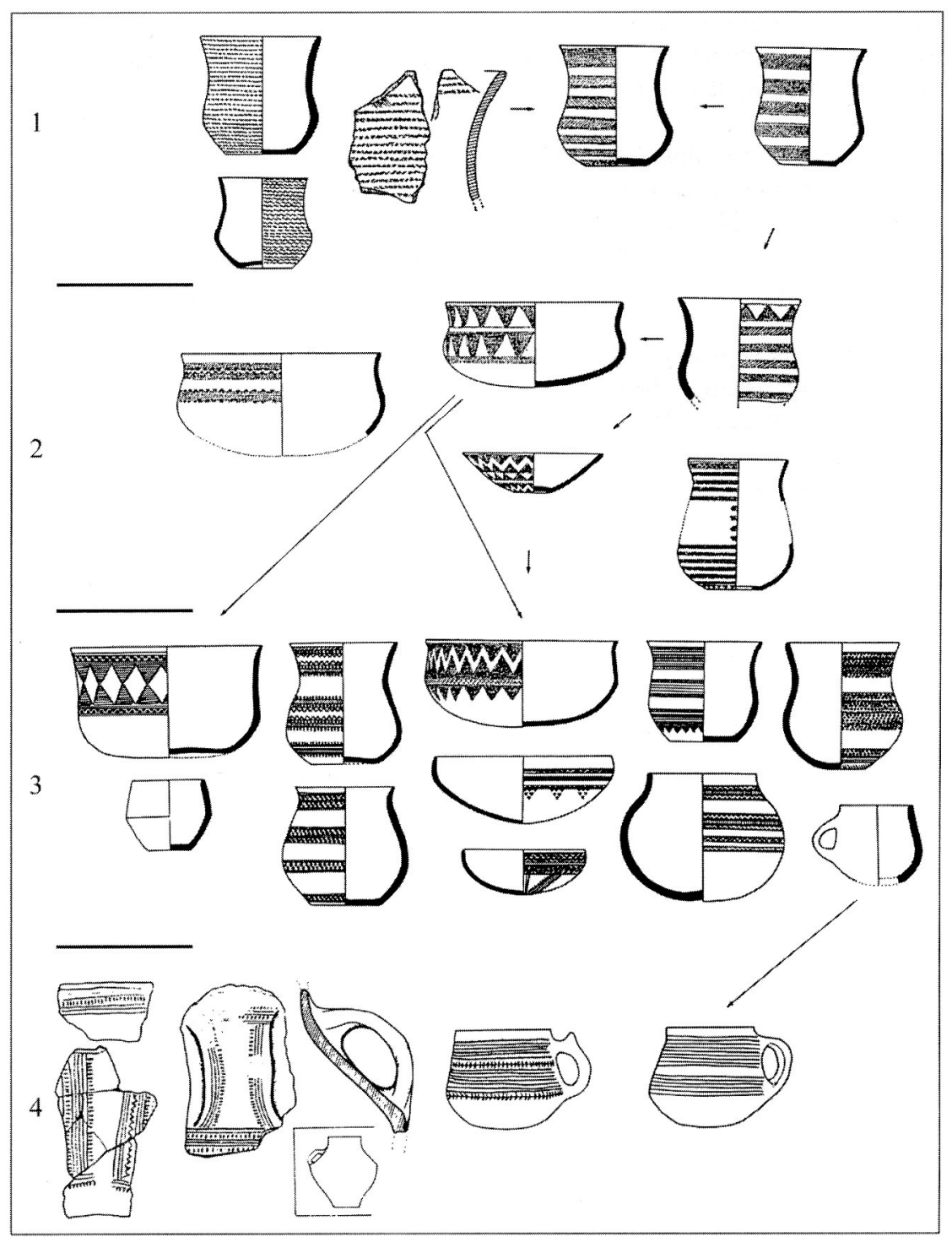

Fig. 3. - Hypothèse d'évolution stylistique de la céramique campaniforme en France méditerranéenne, d'apres J. Guilaine (1976). 


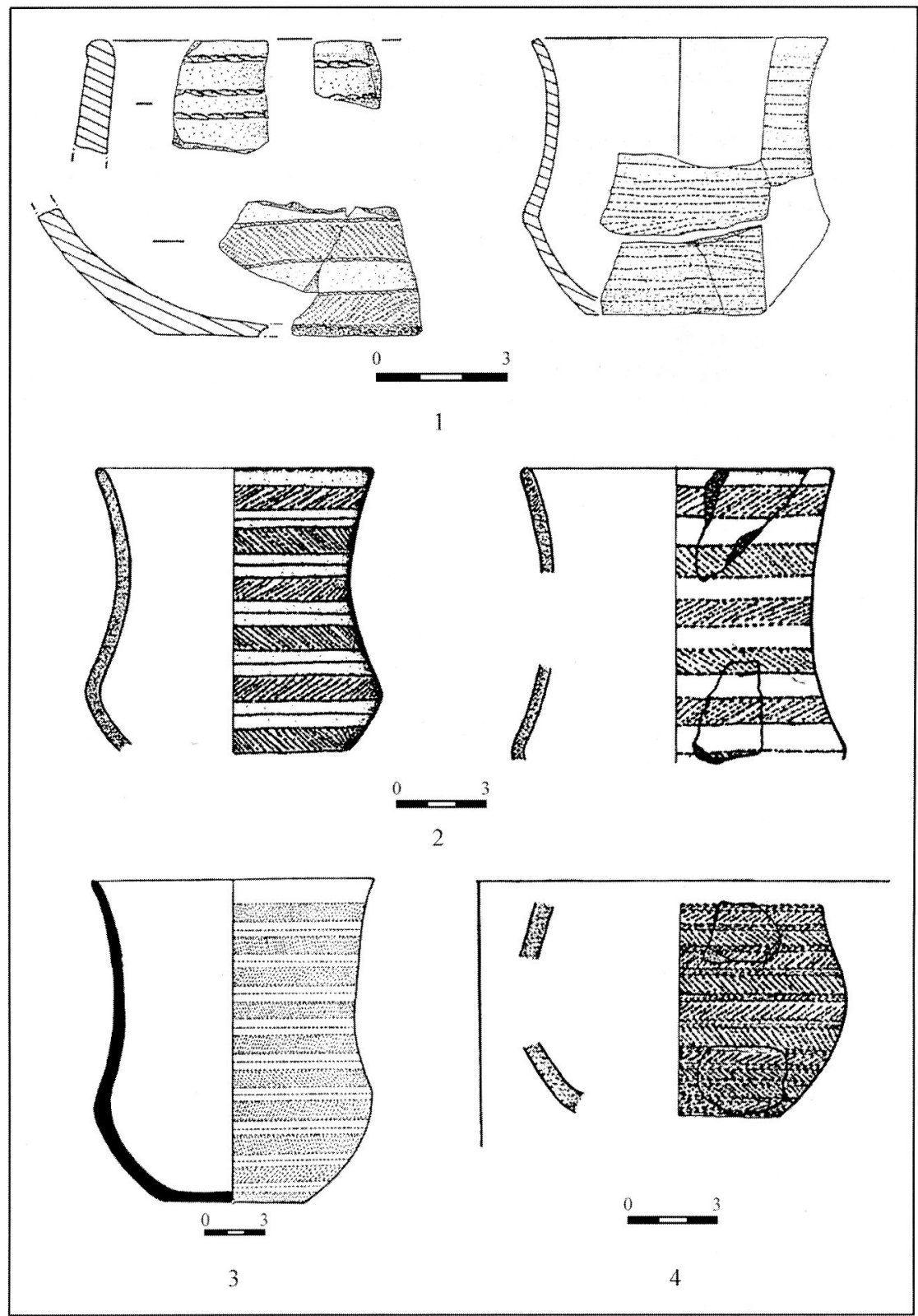

Fig. 4. - Céramique campaniforme ornée attri-buable au Campaniforme ancien. 1 : Sanilhac-SaintVérédème (gard) d'après E. Vigneron ; 2: Donzère-Baume-des-Anges (Drôme) d'après J. Bill ; 3 : Serezin-Abri sépulcral (Isère) d'après F. Claustre; 4: Donzère-Chauve-Souris (Drôme) d'après J. Bill. 


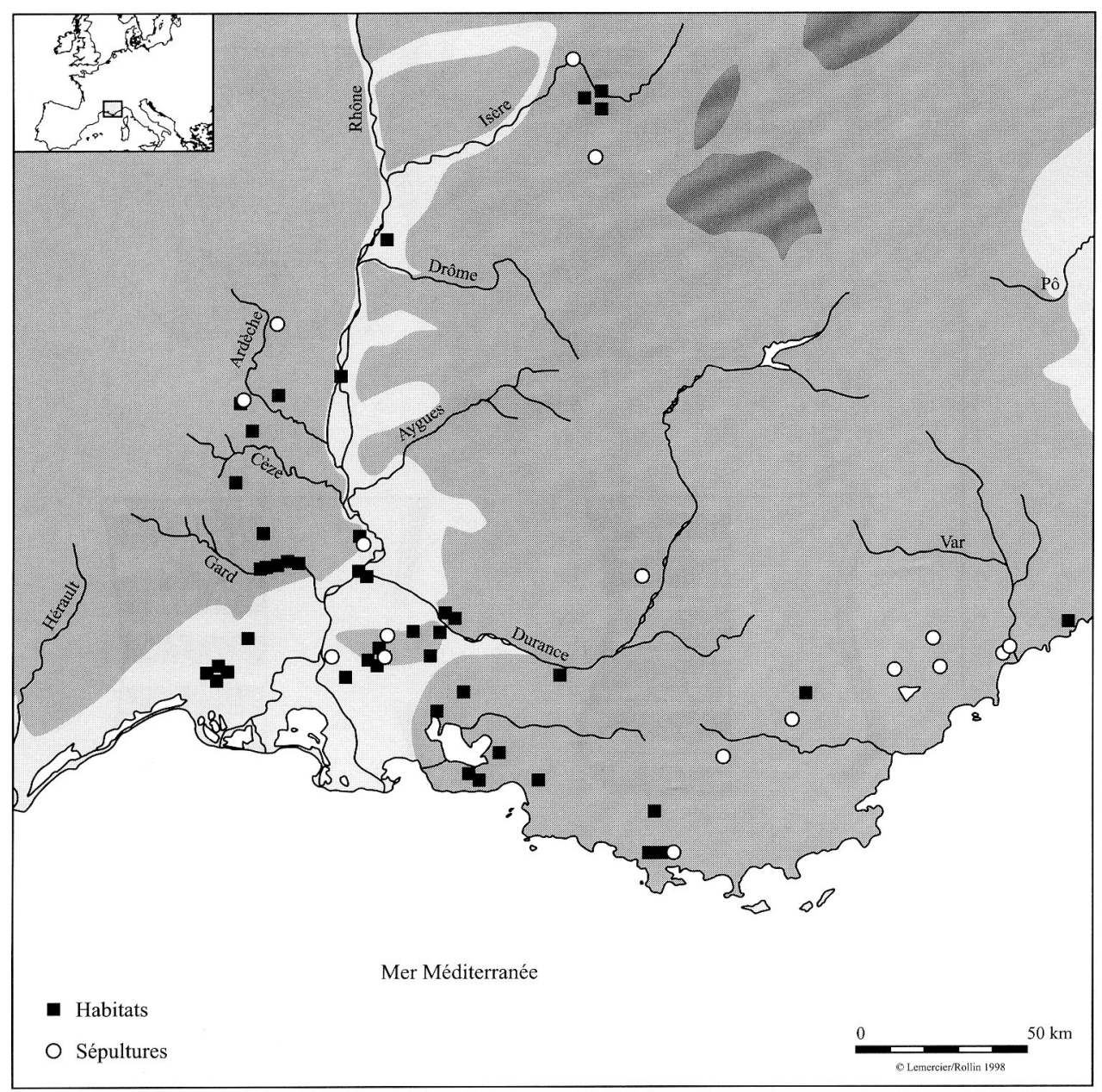

Fig. 5. - Carte de répartition schématique des sites et sépultures à mobilier campaniforme ancien et moyen dans le Sud-Est de la France. 


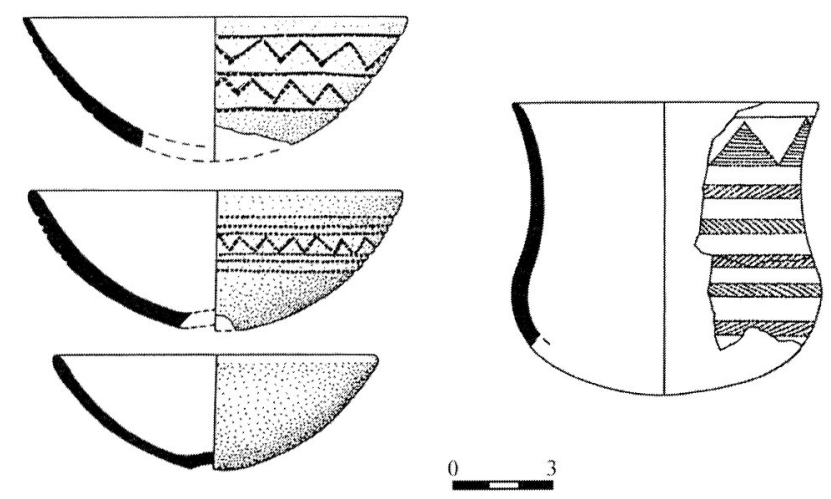

Fig. 6. - Céramique campaniforme attribuable au Campaniforme de la phase 2 de J. Guilaine. Avignon-La Balance (Vaucluse) d'après J. Courtin.

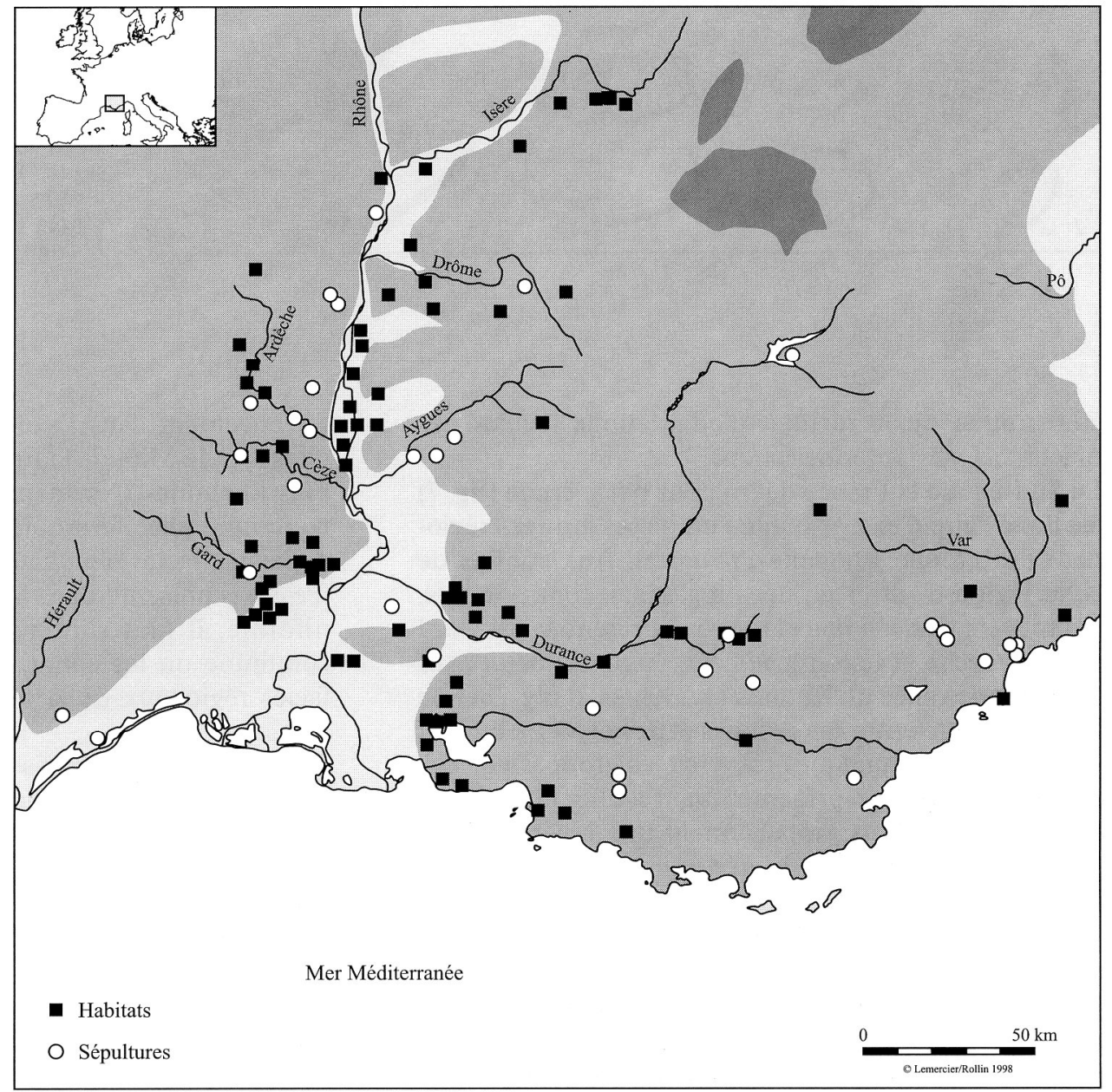

Fig. 7. - Carte de répartition schématique des sites et sépultures à mobilier du Campanifor-me récent du groupe Rhodano-Provençal dans le Sud-Est de la France. 


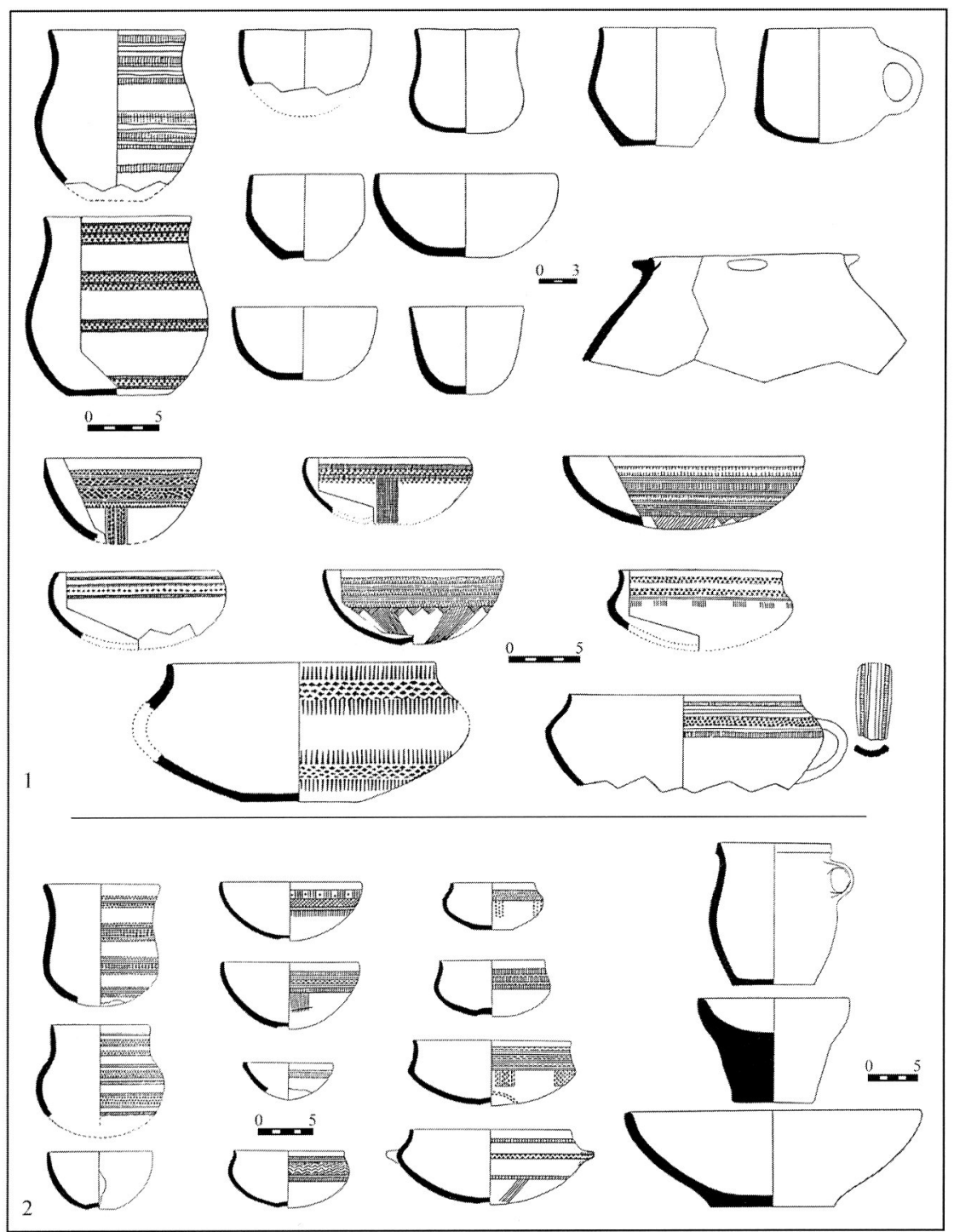

Fig. 8. - Céramique campaniforme attribuable au groupe Rhodano-Provençal de la phase récente. 1 : SaintCôme-Bois Sacré (Gard) d'après J.-L. Roudil ; 2: Montpezat-Grotte Murée (Alpes-de-Haute-Provence) d'après J. Courtin. 


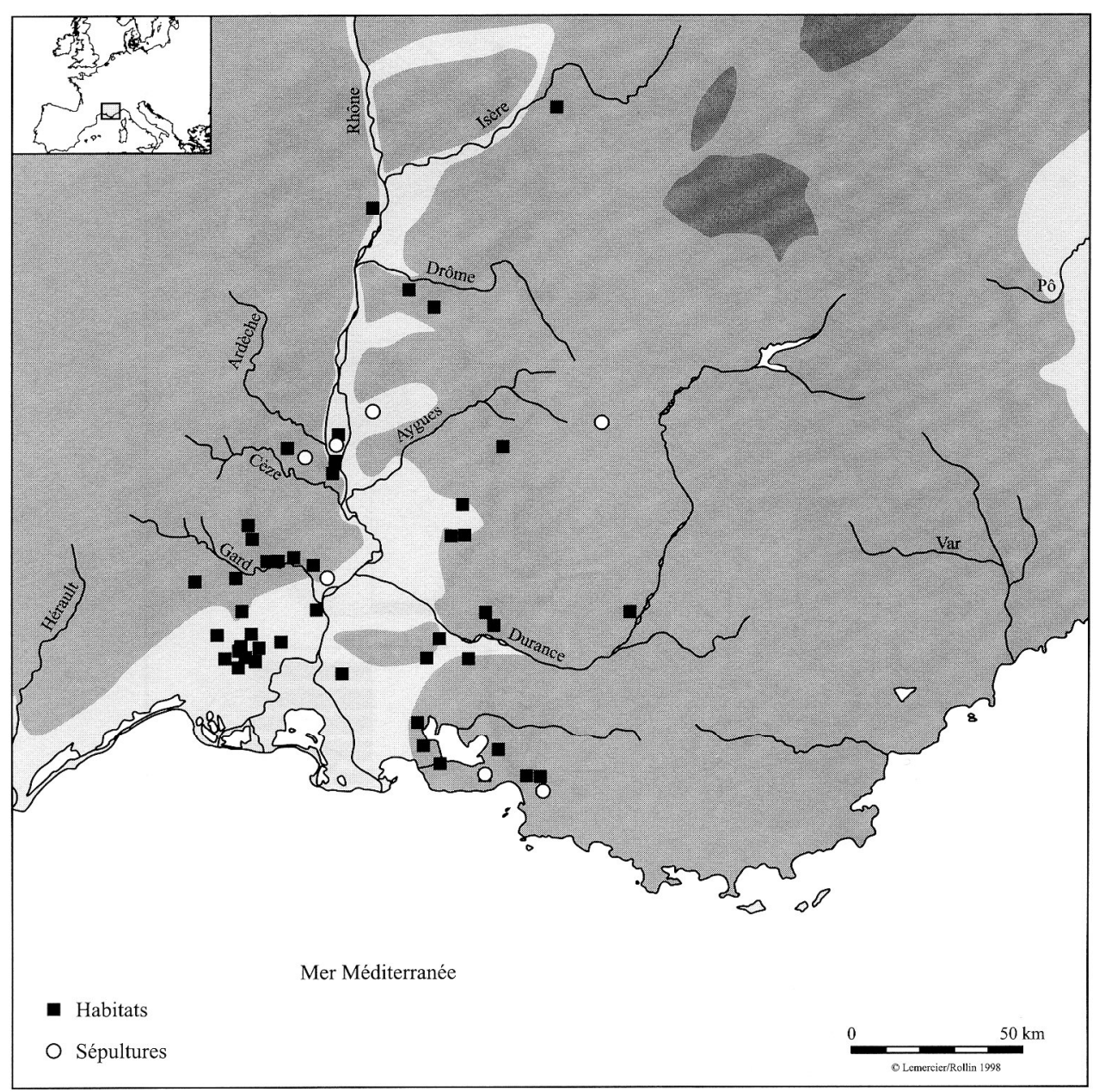

Fig. 9. - Carte de répartition schématique des sites et sépultures à mobilier du Bronze ancien à céramique à décor barbelé (de tradition campaniforme) dans le Sud-Est de la France. 


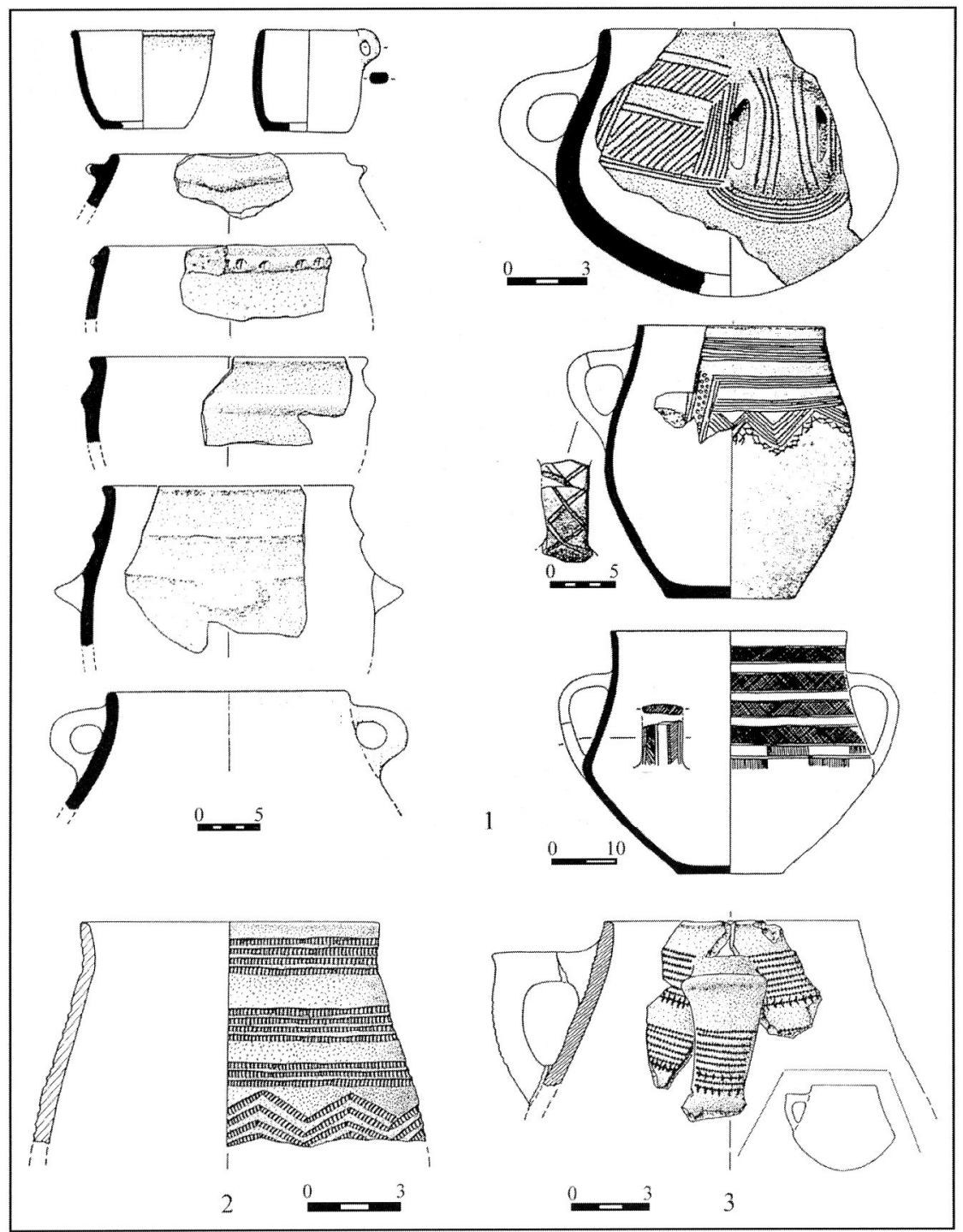

Fig. 10. - Céramique du Bronze ancien à décor barbelé de tradition campaniforme dans le Sud-Est de la france. 1 : Le Rôve-Camp de Laure (Bouches-du-Rhône) d'après J. Courtin ; 2: Lourmarin-Les Lauzières (Vaucluse) d'après A. D'Anna et J. Courtin ; 3 : La Couronne-Collet-Redon (Bouches-duRhône) d'après J. Courtin. 
LEMERCIER O. (1998) - Phénomène, culture et tradition : statuts et rôles du Campaniforme au Ille millénaire dans le sud-est de la France, Bulletin de la Société Préhistorique Française, tome 95, n³, 1998, p. 365-382.

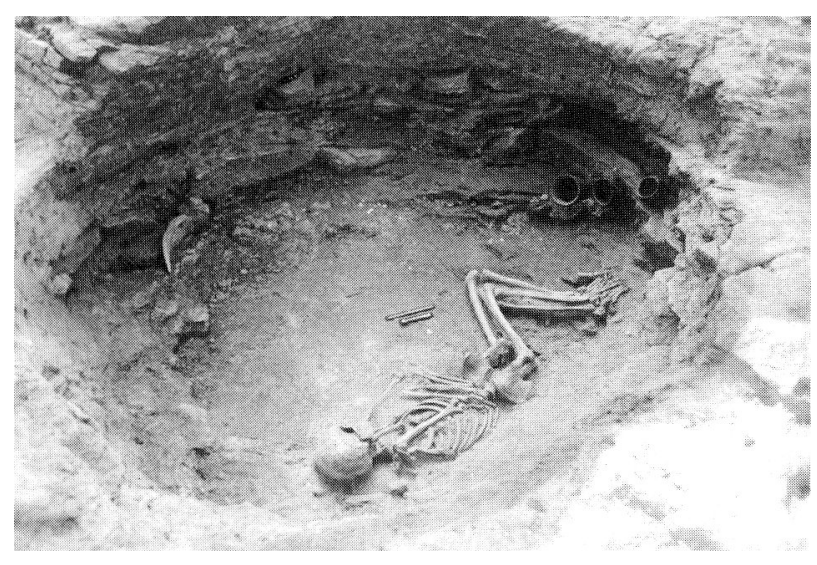

Fig. 11. — Vue de la sépulture de Forcalquier - La Fare (Alpes-de-Haute-Provence) (campaniforme ancien) après la fouille. Fouilles $\mathrm{A}$. Millier et 0 . Lemercier, cliché $\mathrm{O}$. Lemercier.

Fig. 12. - Vue du gobelet campaniforme orné de la sépulture de Forcalquier-La Fare (Alpes-de-HauteProvence). Cliché S.R.A. P.A.C.A. 
LEMERCIER O. (1998) - Phénomène, culture et tradition : statuts et rôles du Campaniforme au Ille millénaire dans le sud-est de la France, Bulletin de la Société Préhistorique Française, tome 95, n³, 1998, p. 365-382.

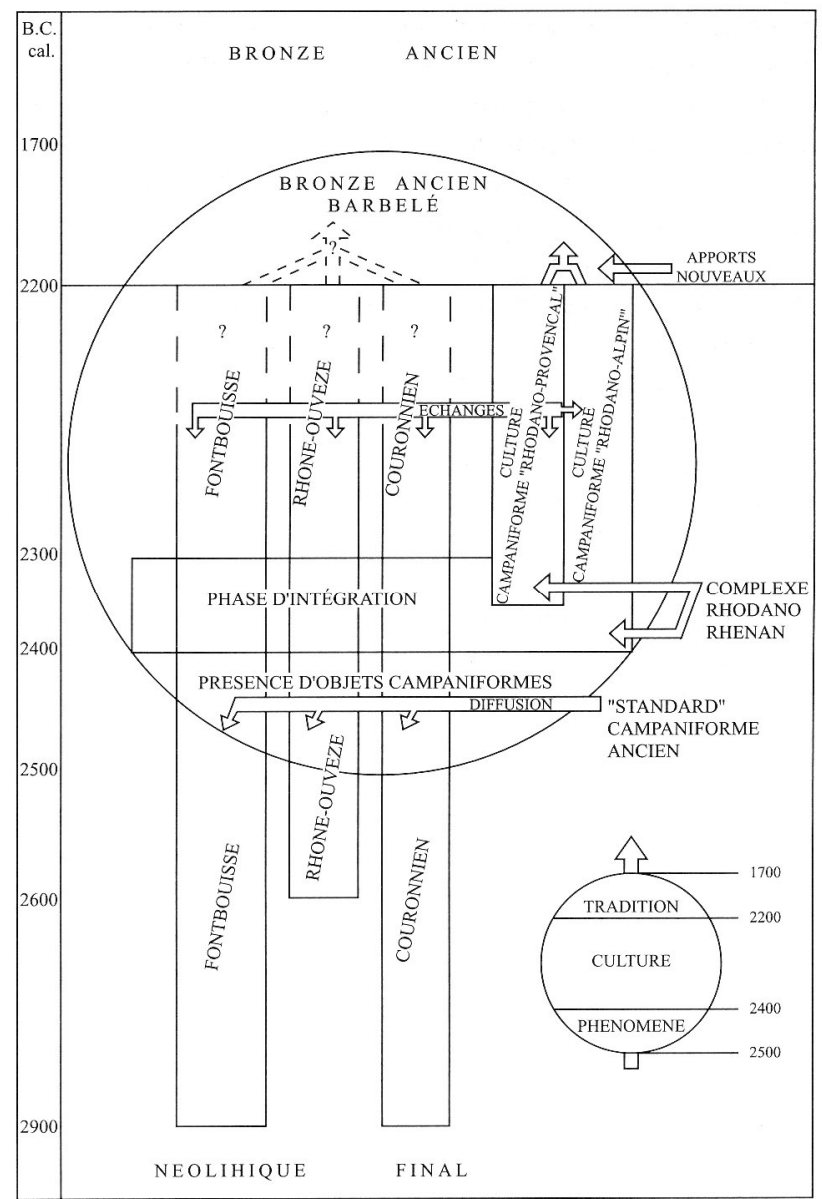

Fig. 13. - Schéma interprétatif de l'insertion du Campaniforme dans le processus d'évolution des groupes culturels au Ille millénaire. 